\title{
Mesenchymal Stem Cell Fate Following Non-viral Gene Transfection Strongly Depends on the Choice of Delivery Vector
}

T Gonzalez-Fernandez ${ }^{1,2,3,8}$, BN Sathy ${ }^{1,2}$, C Hobbs $^{3,4,5}$, GM Cunniffe $^{1,2}$, HO McCarthy ${ }^{6}$, NJ Dunne ${ }^{1,6,7}$, V Nicolosi $^{3,4,5}$, FJ O'Brien ${ }^{1,3,8}$, DJ Kelly $y^{1,2,3,8^{*}}$

${ }^{1}$ Trinity Centre for Bioengineering, Trinity Biomedical Sciences Institute, Trinity College Dublin.

${ }^{2}$ Department of Mechanical and Manufacturing Engineering, School of Engineering, Trinity College Dublin.

${ }^{3}$ Advanced Materials and Bioengineering Research Centre, Trinity College Dublin and Royal College of Surgeons in Ireland.

${ }^{4}$ School of Physics, Trinity College Dublin, Ireland.

${ }^{5}$ Centre for Research of Adaptive Nanostructures and Nanodevices, Trinity College Dublin, Ireland.

${ }^{6}$ School of Pharmacy, Queen's University Belfast, Northern Ireland.

${ }^{7}$ School of Mechanical and Manufacturing Engineering, Dublin City University, Ireland.

${ }^{8}$ Tissue Engineering Research Group, Dept. of Anatomy, Royal College of Surgeons in Ireland.

*Corresponding author: Daniel J Kelly

E-mail: kellyd9@tcd.ie

Trinity Centre for Bioengineering,

152-160 Pearse street,

Dublin 2, Ireland

Phone: +353-1-8963947

Fax: +353-1-6795554 


\section{ABSTRACT}

Controlling the phenotype of mesenchymal stem cells (MSCs) through the delivery of regulatory genes is a promising strategy in tissue engineering (TE). Essential to effective gene delivery is the choice of gene carrier. Non-viral delivery vectors have been extensively used in TE, however their intrinsic effects on MSC differentiation remain poorly understood. The objective of this study was to investigate the influence of three different classes of non-viral gene delivery vectors: (1) cationic polymers (polyethylenimine, PEI), (2) inorganic nanoparticles (nanohydroxyapatite, $\mathrm{nHA}$ ) and (3) amphipathic peptides (RALA peptide) on modulating stem cell fate after reporter and therapeutic gene delivery. Despite facilitating similar reporter gene transfection efficiencies, these nanoparticle-based vectors had dramatically different effects on MSC viability, cytoskeletal morphology and differentiation. After reporter gene delivery (pGFP or pLUC), the nHA and RALA vectors supported an elongated MSC morphology, actin stress fibre formation and the development of mature focal adhesions, while cells appeared rounded and less tense following PEI transfection. These changes in MSC morphology correlated with enhanced osteogenesis following $\mathrm{nHA}$ and RALA transfection and adipogenesis following PEI transfection. When therapeutic genes encoding for transforming growth factor beta 3 (TGF- $\beta 3$ ) and/or bone morphogenic protein 2 (BMP2) were delivered to MSCs, nHA promoted osteogenesis in 2D culture and the development of an endochondral phenotype in 3D culture, while RALA was less osteogenic and appeared to promote a more stable hyaline cartilage-like phenotype. In contrast, PEI failed to induce robust osteogenesis or chondrogenesis of MSCs, despite effective therapeutic protein production. Taken together, these results demonstrate that the differentiation of MSCs through the application of non-viral gene delivery strategies depends not only on the gene delivered, but also on the gene carrier itself.

KEY WORDS: non-viral gene delivery; nanoparticle-based gene delivery vectors; MSC differentiation; MSC transfection

\section{INTRODUCTION}

Adult mesenchymal stem cells (MSCs) are a promising cell source for regenerative medicine due to their multipotent differentiation capacity [1] and immunomodulatory properties [2]. Controlling the phenotype of MSCs is a central challenge in tissue engineering and regenerative medicine. The fate of progenitor cells can potentially be modulated through the introduction of exogenous genes for the cell-mediated synthesis of specific proteins. This approach may be preferable over the delivery of recombinant cytokines and growth factors which involves the administration of non-physiological concentrations, due to the short half-life and fast body clearance and a lower therapeutic effect in comparison to natural proteins [3-5]. A variety of genes have been explored to this end, including 
members of the transforming growth factor-beta (TGF- $\beta$ ) superfamily of proteins such as bone morphogenic protein 2 (BMP2) and transforming growth factor-beta 3 (TGF- $\beta 3$ ), whose overexpression has been previously reported to enhance bone and cartilage regeneration in vivo [6-8]. But the success of gene therapy ultimately depends on the gene delivery mechanism to maximise nucleic acid uptake and, consequently, downstream protein production [3,4,9-11].

Traditionally, viral vectors such as retrovirus, lentivirus and adenovirus, have been used for the delivery of genes into cells via a process known as transduction $[10,12,13]$. Although they offer high transduction efficiencies and stable gene expression, many limitations remain associated with viral vectors [14-16] such as insertional mutagenesis [17], immunogenicity [11], limited DNA packaging capacity [18] and cumbersome large-scale production [19]. Non-viral gene carriers are promising alternatives for gene delivery and have the potential to address these limitations [9]. Moreover, the transient expression associated with these systems can be more compatible with the natural wound healing processes [20]. Several non-viral vectors are commonly used for gene delivery, including lipids, polymers, cell penetrating peptides (CPPs) and inorganic nanoparticles [13]. While such systems can be used to efficiently transfect cells with specific genes, the effects that these nonviral vectors have on stem cell fate remains relatively unknown $[21,22]$.

Cationic lipid-based and polymeric DNA vectors such as lipofectamine and polyethylenimine (PEI) are amongst the most widely used non-viral gene delivery methods $[13,22,23]$, and are often used as a gold standard for non-viral gene transfection [3]. However their potential cytotoxicity [13,24] and sensitivity to media supplementation with serum and antibiotics [25] limits their use in tissue engineering applications. Among alternative options, inorganic nanoparticles made of calcium phosphate, gold or silica, have been drawing attention for their use in tissue engineering due to their biocompatibility, wider availability, long-term stability, ease of preparation and low toxicity [3,26-28]. More recently, different classes of peptides $[29,30]$, such as the RALA amphipathic peptide (RALA) comprised of repeating arginine/alanine/leucine/alanine units [30], have been developed as novel nucleic acid carriers [31,32], showing excellent cytocompatibility and moderate transfection efficiencies in vivo and in vitro $[30,33]$. These non-viral delivery vehicles are promising in terms of compatibility and transfection efficiency, however the suitability of a gene delivery vector for stem cell-mediated tissue engineering is not only determined by its transfection efficiency, cytocompatibility and levels of expression of the gene product, but also by its chemical composition and how the intracellular delivery of such nanomaterials may influence stem cell fate [22].

Therefore, the objective of this study was to first compare the capacity of three different classes of non-viral gene delivery vectors (PEI, nanohydroxyapatite ( $\mathrm{nHA}$ ) and RALA) to transfect bone 
marrow-derived MSCs. The impact of intracellular delivery of such nanomaterials on the viability, cytoskeletal structure and multi-lineage differentiation potential of MSCs was assessed. We then used these vectors to deliver BMP2 and TGF- $\beta 3$ genes to MSCs as a means to promote either osteogenesis or chondrogenesis in a 2D or 3D environment, and investigated the influence of different gene carriers on MSC lineage commitment. Collectively the results of this study demonstrate that gene vectors with comparable capacities to transfect MSCs with reporter and therapeutic genes can have dramatically different effects on MSC differentiation.

\section{MATERIALS AND METHODS}

\subsection{Plasmid propagation}

Four different plasmids were used in the current study: two plasmids encoding for the reporter genes green fluorescent protein (pGFP, Amaxa, Lonza Cologne AG, Germany) and luciferase (pLUC, pGaussia Luciferase; New England Biolabs, Massachusetts, USA), and another two encoding for the therapeutic genes BMP2 (donation from Prof. Kazihusa Bessho, Kyoto University, Japan) and TGF-ß3 (InvivoGen, Ireland). Plasmid amplification was performed by transforming chemically competent Escherichia coli bacterial cells (One Shot TOP10; Biosciences, Ireland) according to the manufacturer's protocol. The transformed bacteria were cultured on LB plates with $50 \mathrm{mg} / \mathrm{L}$ kanamycin (Sigma-Aldrich, Ireland) as the selective antibiotic for pGFP and $100 \mathrm{mg} / \mathrm{L}$ ampicillin (Sigma-Aldrich, ireland) as the selective antibiotic for pLUC, pTGF- $\beta 3$, and pBMP2. Bacterial colonies were harvested and inoculated in LB broth (Sigma-Aldrich, Ireland) and incubated overnight for further amplification. The harvested bacterial cells were then lysed, and the respective pDNA samples were purified using qiagen plasmid kit (MaxiPrep Kit; Qiagen, Ireland). Nucleic acid concentration $(\mathrm{ng} / \mu \mathrm{L}$ ) was determined by analyzing the 260:280 ratio and $230 \mathrm{~nm}$ measurement using NanoDrop spectrophotometer (Labtech International, Uckfield, UK). Plasmids in this study were used at a concentration of $0.5 \mu \mathrm{g}$ plasmid in $1 \mu \mathrm{L}$ Tris-EDTA (TE) buffer.

\subsection{Preparation of delivery vectors and vector-pDNA complexes}

The synthesis of the nHA particles was performed as previously described [34]. Briefly, a solution of $12 \mathrm{mM}$ sodium phosphate (Sigma-Aldrich, Ireland), containing 0.017\% DARVAN821A (RTVanderbilt, Norwalk, USA) was added to an equal volume of a $20 \mathrm{mM}$ calcium chloride solution (Sigma-Aldrich, Ireland) and filtered through a $0.2 \mathrm{~mm}$ filter (Fisher, Ireland). nHA-pDNA complexes were prepared by adding $150 \mu \mathrm{L}$ of the $\mathrm{nHA}$ solution to $2 \mu \mathrm{g}$ of pDNA pretreated with $0.25 \mathrm{M} \mathrm{CaCl} 2$ (Sigma-Aldrich, Ireland) as previously optimized [26,27]. The nHA-pDNA solutions were not incubated prior to transfection in order to avoid particle aggregation that could impair cellular uptake as previously optimized [26]. 
PEI-pDNA complexes were prepared using branched PEI with a molecular weight of 25kDA (SigmaAldrich, Ireland). PEI was condensed with pDNA in an N:P ratio (the molar ratio of positively charged nitrogen atoms in the PEI to negatively charged phosphates in the PDNA backbone) of 7, a ratio previously optimized for MSC transfection [35]. The PEI-pDNA solution was then incubated for 30 minutes for complex formation.

The RALA peptide was synthesised as previously described [30]. Briefly, the peptide was produced by 9-fluorenylmethyloxycarbonyl (Fmoc) solid-state peptide synthesis (Biomatik, USA) and supplied as a desalted, lyophilised powder. The product was purified and validated by reversed-phase highperformance liquid chromatography (RPHPLC); molecular mass was confirmed as 3327.98. The RALApDNA complexes were prepared at N:P ratio of 6, previously optimized to achieve low cytotoxicity and high transfection efficiency [30,33]. The RALA-pDNA solution was then incubated for 30 minutes for complex formation.

\subsection{Determination of size and zeta potential of the nanoparticles-pDNA complexes}

The morphology of the nHA-pDNA, PEI-pDNA and RALA-pDNA complexes were characterized using transmission electron microscopy (TEM). The nHA-pDNA sample was prepared by placing $5 \mu \mathrm{L}$ droplet onto a Formvar/SiO TEM Cu grid (Agar Scientific, UK) and allowed to air dry overnight. Similarly, the PEI-pDNA and RALA-pDNA were prepared on holey-carbon film CU TEM grids and post-stained with $5 \%$ uranyl acetate as previously described [30]. nHA-pDNA and PEI-pDNA vectors were characterized using an FEI Titan TEM (FEI, USA) operating at 300 kV. RALA-pDNA was characterized using a JEOL CXII TEM (JEOL, USA) operating at $80 \mathrm{kV}$. The size and zeta potential of the complexes were assessed using a Nano ZS Zetasizer and DTS software (Malvern Instruments, UK).

\subsection{Isolation and expansion of bone marrow-derived MSCs}

Bone marrow-derived MSCs were isolated from the femora of porcine donors (3-4 months, $>50 \mathrm{Kg}$ ) within $3 \mathrm{~h}$ of sacrifice according to a modified method developed for human MSCs[36]. Mononuclear cells were plated at a seeding density of $5 \times 10^{3}$ cells $/ \mathrm{cm}^{2}$ in standard culture media, high glucose Dulbecco's modified Eagle's medium $(4.5 \mathrm{mg} / \mathrm{mL}$ d-glucose and $200 \mathrm{mM}$ L-glutamine; hgDMEM) supplemented with $10 \%$ fetal bovine serum $(F B S)$ and penicillin $(100 \mathrm{U} / \mathrm{mL})$-streptomycin $(100 \mathrm{~g} / \mathrm{mL})$ (all from Gibco, Biosciences, Ireland), and expanded in a humidified atmosphere at $37{ }^{\circ} \mathrm{C}, 5 \% \mathrm{CO}_{2}$, and $20 \% \mathrm{pO}_{2}$. MSCs at passage 2 were used for all experiments.

\subsection{MSC transfection}

Expanded MSCs were plated at a seeding density of $5 \times 10^{4}$ cells $/ \mathrm{cm}^{2}$ in 6 well plates and cultured for 24 hours in standard culture media prior to transfection. pDNA-vector complexes were prepared 
immediately before transfection. For the RALA-pDNA and PEI-pDNA transfections [30,35], the plated cells were washed with PBS and incubated in 1-2 ml of Opti-MEM (Life Technologies, Ireland) for $2 \mathrm{~h}$. After the incubation time, complexes were suspended in $500 \mu \mathrm{L}$ of Opti-MEM and added to MSCs to a density of $0.2 \mu \mathrm{g}$ of DNA $/ \mathrm{cm}^{2}$. Following incubation for $5 \mathrm{~h}$, the media was removed and replaced with standard culture media. For the nHA-pDNA transfections [26], complexes were suspended in 500 $\mu \mathrm{L}$ of standard media and added to MSCs to a density of $0.2 \mu \mathrm{g}$ of $\mathrm{DNA} / \mathrm{cm}^{2}$, residual complexes were removed after $4 \mathrm{~h}$ of incubation and replaced with standard culture media.

\subsection{Assessment of transfection efficiency}

In order to evaluate the transfection efficiency, pDNA encoding the GFP gene was prepared, complexed with each of the three vectors (section 2.2) and MSCs were transfected as described above. Transfection efficiency was determined by quantifying the percentage of green fluorescent cells at days 3 and 7 post transfection using flow cytometry (BD FACSCALIBUR system, BD Biosciences, UK).

\subsection{Assessment of cell viability and metabolic activity}

After 1 and 3 days of nHA-, PEI- or RALA-mediated gene delivery, metabolic activity of treated cells was evaluated using standard Alamar Blue (Biosciences, Ireland) assay. For the assay, cell culture media from the wells was replaced, at specific time points, with $10 \%$ Alamar Blue containing standard culture media ( $1 \mathrm{~mL} /$ well) and were incubated for $4 \mathrm{~h}$ at $37^{\circ} \mathrm{C}$. After the incubation time, $200 \mu \mathrm{L}$ of the supernatant was plated in triplicate into a 96-well plate; absorbance was read at 570 and $600 \mathrm{~nm}$ using a plate reader (Bioteck, Instruments Inc, UK). Optical density of the media was translated to cell metabolic activity relative to the untransfected control as previously described [37].

\subsection{Fluorescent imaging and cell morphology analysis}

Qualitative and semi-quantitative analysis of cell morphology was performed on nHA-pGFP, PEI-pGFP and RALA-pGFP transfected cells. Cells were imaged at day 1 and 3 after transfection using an inverted epifluorescent microscope (Olympus IX83, Germany). Cell morphology was assessed semiquantitatively through the calculation of the cell surface area, aspect ratio and circularity using ImageJ software, $n=4$ and 6 pictures per sample.

Analysis of actin cytoskeleton and focal adhesion points on vector-pLUC transfected cells were performed by actin and vinculin immunofluorescent staining. At day 1 and 3 after transfection, MSCs previously seeded on $\mu$-slide 4 well IBItreat chambers (IBIDI, Germany), were fixed in $4 \%$ paraformaldehyde (PFA) (Sigma-Aldrich, Ireland) for $15 \mathrm{~min}$ at room temperature (RT). Samples were first blocked with $5 \%$ bovine serum albumin (BSA) and incubated overnight with vinculin primary antibody (AB) (1:500 a mouse monoclonal anti-vinculin) (Abcam, ab18058, Ireland) at $4^{\circ} \mathrm{C}$. After 
incubation, samples were permeabilised with $0.5 \%$ Triton X-100 (Sigma-Aldrich, Ireland) and incubated with secondary AB (1:250 a mouse Alexa Fluor 488 lgG) (Biosciences, Ireland) and stained with rhodamine phalloidin (VWR, Ireland) for $1 \mathrm{~h}$ at RT. Cell nuclei were stained with DAPI (VWR, Ireland) for $10 \mathrm{~min}$ at RT, washed in PBS and were imaged using confocal microscopy (Leica SP8, Ireland).

\subsection{Osteo-adipo and chondrogenic differentiation of MSCs}

For evaluating osteo-adipo lineage differentiation of MSCs, transfected MSCs and the non-treated controls were maintained in standard culture media for a period of $24 \mathrm{~h}$ followed by 14 days in osteoadipo bi-potent media at $20 \% \mathrm{O}_{2}$ and $37^{\circ} \mathrm{C}$. Osteo-adipo bi-potent media[38] was prepared by mixing osteogenic media (standard culture media containing $\beta$-glycerolphosphate $(10 \mathrm{mM})$, dexamethasone $(100 \mathrm{nM})$ and L-ascorbic acid-2-phosphate $(0.05 \mathrm{mM})$ with adipogenic media (standard culture media containing dexamethasone (100 mM), isobutyl-1-methyl xanthine (IBMX) (0.5 mM) and indomethacin $(50 \mu \mathrm{M})$ (all from Sigma-Aldrich, Ireland) at 1:1 ratio. Culture media was replaced twice weekly. Negative controls (untransfected and transfected cells in standard culture media) were also maintained in parallel.

For evaluating chondrogenic differentiation of MSCs, transfected MSCs and the non-treated controls maintained in standard culture media for a period of $24 \mathrm{~h}$ were pelletized by centrifugation at 2000 rpm at a cell density of $250 \times 10^{3}$ cells/pellet. Pellets were maintained in a chemically defined medium consisting of DMEM GlutaMAX supplemented with penicillin $(100 \mathrm{U} / \mathrm{mL})$-streptomycin $(100 \mathrm{mg} / \mathrm{mL})$, $100 \mathrm{mg} / \mathrm{mL}$ sodium pyruvate, $40 \mathrm{mg} / \mathrm{mL}$ I-proline, $50 \mathrm{mg} / \mathrm{mL}$ l-ascorbic acid-2-phosphate, $1.5 \mathrm{mg} / \mathrm{mL}$ BSA, 1 x insulin-transferrin-selenium, and $100 \mathrm{nM}$ dexamethasone (all from Sigma-Aldrich, Ireland) at $20 \% \mathrm{pO}_{2}$ and $37^{\circ} \mathrm{C}$ for a period of 21 days. Half media changes (only half the media was changed) were performed twice weekly. No exogenous recombinant growth factors were added to the culture media.

\subsection{Gene expression analysis}

Transfected and control cells after 7 days of in vitro culture were lysed using R lysis buffer (Qiagen, UK) supplemented with $10 \mu \mathrm{L} \mathrm{mL}^{-1} \beta$-mercaptoethanol (Sigma-Aldrich, Ireland) and stored at $-80^{\circ} \mathrm{C}$. Lysates were thawed and homogenized using a QIAshredder column (Qiagen, UK) and total RNA was isolated and purified using the RNeasy mini kit (Qiagen, UK) using the manufacturer suggested protocol. Purity and yield of RNA was quantified using the NanoDrop Spectrophotometer (Labtech International, Uckfield, UK). For cDNA preparation, $50 \mathrm{ng}$ total RNA of each sample was reverse transcribed into cDNA per $20 \mu \mathrm{L}$ of reaction volumes using the high capacity reverse transcription 
cDNA kit (Applied Biosystems, Paisley, UK) as per manufacturer's instructions. Quantitative PCR was performed using an ABI 7500 sequence detection system (Applied Biosystems, Paisley, UK) and SYBR select master mix (Applied Biosystems, Paisley, UK) for evaluating the expression SRY-box-9 (SOX9), Runt related transcription factor 2 (RUNX2), Aggrecan (ACAN), and Glyceraldehyde-3-phosphate dehydrogenase (GAPDH) genes. Primer sequences that were used for amplification of these genes are listed in Table 1. Comparative Threshold (cT) data were analysed using the $\Delta \Delta C T$ method as described previously [39] with GAPDH as the endogenous control. Relative expression of the genes is presented as fold changes relative to the control group.

Table 1. Primer sequences used for real-time PCR

\begin{tabular}{ccc}
\hline Gene & Forward primer & Reverse primer \\
\hline RUNX2 & CCAACAGAGGCATTTAAGG & CCAAAAGAAGTTTTGCTGAC \\
\hline SOX9 & CAGACCTTGAGGAGACTTAG & GTTCGAGTTGCCTTTAGTG \\
\hline ACAN & GACCACTTTACTCTTGGTG & TCAGGCTCAGAAACTTCTAC \\
\hline GAPDH & TTTAACTCTGGCAAAGTGG & GAACATGTAGACCATGTAGTG \\
\hline
\end{tabular}

2.11. BMP2 and TGF- $\beta 3$ protein expression quantification

The levels of BMP2 and TGF- $\beta 3$ in the culture medium expressed by nHA, PEI and RALA transfected MSCs were quantified using ELISAs (R\&D Systems). The cell culture supernatant was collected and analyzed at day 3 and 7. Assays were carried out according to the manufacturer's instructions, and the absorbance of each sample was read at $450 \mathrm{~nm}$ using a plate reader, whereby the quantity of either BMP2 or TGF- $\beta 3$ protein present was deduced by calculating against a standard curve.

\subsection{Quantitative biochemical analysis}

Monolayers were lysed using Cell Lytic (Sigma-Aldrich, Ireland) and pellets were digested with papain (125 mg/mL, pH 6.5) in 0.1 M sodium acetate, $5 \mathrm{nM} \mathrm{L-cysteine} \mathrm{HCl}$, and 0.05 M EDTA (all Sigma-Aldrich, Ireland) at $60^{\circ} \mathrm{C}$ under constant rotation for $18 \mathrm{~h}$. Calcium content was determined using a Sentinel Calcium Kit (Alpha Laboratories Ltd, UK) after digestion in $1 \mathrm{M} \mathrm{HCl}$ at $110^{\circ} \mathrm{C}$ for $48 \mathrm{~h}$. Proteoglycan content was estimated by quantifying the amount of sulfated glycosaminoglycan (sGAG) in the pellets using the dimethylmethylene blue (DMMB) dye-binding assay (Blyscan, Biocolor Ltd. Northern Ireland), with a chondroitin sulfate standard. Total collagen content was determined by measuring the hydroxyproline content. Samples were hydrolyzed at $110^{\circ} \mathrm{C}$ for $18 \mathrm{~h}$ in concentrated $\mathrm{HCl} 38 \%$, allowed 
to dry, and analyzed using a chloramine-T assay [40] with a hydroxyproline-to-collagen ratio of 1:7.69[41]. Four samples per group were analyzed for each biochemical assay.

\subsection{Histological and immunohistochemical analysis}

To evaluate mineral deposition, cells in monolayer culture at day 14 were fixed in $100 \%$ ethanol and stained with $1 \%$ alizarin red (AR) (Sigma-Aldrich, Ireland). Stained samples were air dried and images were captured using phase transmission microscope (Olympus, UK). Semi-quantitative analysis of AR staining was done through extraction of the dye using $10 \%$ cetylpyridinium chloride (Sigma-Aldrich, Ireland) and measuring the absorbance at $540 \mathrm{~nm}[42]$.

For evaluating oil droplets, cells were fixed in 4\% PFA and stained with Oil-Red-O (ORO) at day 14. Semi-quantitative analysis of ORO staining was done through extraction of the dye using $100 \%$ isopropanol (Sigma-Aldrich, Ireland) and measuring the absorbance at $490 \mathrm{~nm}$.

For evaluating sGAG, calcium and collagen deposition, cell pellets were fixed with 4\% PFA after 21 days in vitro, wax embedded, sliced $(8 \mu \mathrm{m})$ and mounted on microscopic slides. The sections were stained with $1 \%$ AR to assess calcium accumulation and Alcian blue (Sigma-Aldrich, Ireland) to assess sGAG content. Collagen types I, II and X were evaluated using a standard immunohistochemical technique as described previously [43]. Negative (porcine cartilage and ligament for collagen type $\mathrm{X}$, and growth plate for collagen type I and II) and positive controls (cartilage for collagen type II, ligament for collagen type I and growth plate for collagen type X) were included for each immunohistochemical analysis.

\subsection{Statistical analysis}

Statistical analyses were performed using GraphPad Prism (version 5) software. One-way ANOVA was used for analysis of variance with Tukey's post hoc test to compare between groups. Numerical and graphical results are displayed as mean \pm standard deviation. Significance was accepted at a level of $p$ $<0.05$.

\section{RESULTS}

\subsection{Particle size and Zeta potential of the nHA-pGFP, PEI-pGFP and RALA-pGFP complexes}

Following conjugation with pGFP, the $\mathrm{nHA}, \mathrm{PEI}$ and RALA complexes were found to be of different size (Fig.1A), charge (Fig.1B) and shape (Fig.1C, D and E). nHA-pGFP complexes were on average larger in size $(\sim 300 \mathrm{~nm})$ and had a negative zeta potential. In contrast, the PEI-pGFP and RALA-pGFP complexes were smaller (>150 nm) and had a positive charge. TEM analysis showed aggregation of the 
nHA-pGFP complexes (Fig.1.C), while PEI-pGFP (Fig.1.D) and RALA-pGFP (Fig.1.E) complexes exhibited a uniform shape and distribution with less aggregation.

\section{2. nHA, PEI and RALA possess similar capacities to transfect MSCs but have unique effects on metabolic activity and cellular morphology}

All 3 gene delivery vectors demonstrated similar transfection efficiencies of approximately $15-20 \%$ at day 3 (Fig.2.A). However, 7 days after treatment, the percentage of GFP positive cells decreased in the nHA and RALA transfected groups while it stayed constant in the PEl group (Fig.2.A). The metabolic activity of treated cells significantly decreased in the PEI group at day 1 in comparison to the RALA and nHA groups (Fig.2B). GFP positive cells were imaged at day 1 and 3 after transfection (Fig.2C) and the cell surface area (Fig.2.D), circularity (Fig.2.E) and cell aspect ratio (Fig.2.F) of the transfected cells were assessed at the two different time points. GFP positive MSCs transfected by nHA-pGFP or RALA-pGFP complexes displayed an elongated and spread morphology, while MSCs transfected by PEI-pGFP complexes appeared more rounded (Fig2.C). Quantitative analysis of the images confirmed a significantly higher cell surface area (Fig.2.D) and cell aspect ratio (Fig.2.F) in MSCs transfected by nHApGFP or RALA-pGFP complexes and significantly higher circularity in MSCs transfected by PEI-pGFP complexes (Fig.2.C).

Immunofluorescent imaging of cells treated with either nHA, PEI or RALA, complexed to pDNA encoding for luciferase (pLUC) and stained for vinculin (green), F-actin (red) and nuclei (blue), revealed the presence of more well developed and intensely stained actin stress fibers and a higher number of mature focal adhesions in the nHA (Fig.3.B and F) and RALA (Fig.3.D and H) in comparison to PEI transfected MSCs (Fig.3. C and G). It also confirmed the effects of PEl on cell morphology, where MSCS appeared smaller with minimal spreading in comparison to the elongated MSCs when nHA and RALA were used as gene delivery vectors (Fig.3).

\subsection{The choice of gene delivery vector influences osteo-adipo lineage specification in MSCs}

Delivery of plasmid DNA encoding for the reporter gene GFP (pGFP) to MSCs in 2D culture resulted in significantly enhanced calcification (Fig. 4.A and D) when $\mathrm{nHA}$ and RALA were used as transfection vectors in comparison to the PEI transfected group and untransfected controls after 14 days maintained in mixed osteo-adipo media. In both the nHA and RALA transfected groups, GFP positive cells formed aggregates at day 14 (Fig.4.C) confirming the presence of transfected cells in the mineralized nodules observed after calcium staining (Fig.4.A). In contrast, the PEI transfected cells tended to undergo adipogenesis, as demonstrated by a higher presence of lipid granules in comparison 
to the control and the $\mathrm{nHA}$ and RALA groups (Fig.4.B and E). No mineralized nodules were observed in PEl transfected cells (Fig.4.A and C).

\subsection{Osteogenesis of MSCs after therapeutic gene delivery is highly dependent on the choice of} gene delivery vector and does not correlate with therapeutic protein production

Therapeutic gene delivery of pDNA encoding for either TGF- $\beta 3$ or BMP2 in combination or isolation to MSCs in 2D culture resulted in effective protein production using the three vectors (Fig.5.A and B). At day 3, the highest levels of protein were produced using RALA and PEI as the delivery vector, while at day 7 the highest levels were observed with PEI with low levels of protein production measured using nHA or RALA as the delivery vector (Fig.5.A and B). Although nHA-mediated transfection led to significantly lower overall levels of TGF- $\beta 3$ (Fig.5.A) and BMP2 protein production (Fig.5.B), it resulted in the highest levels of mineral deposition after 14 days of 2D in vitro culture under basal media conditions in comparison to the RALA and PEI groups and the nHApGFP control (Fig.5.C and D).

\subsection{Chondrogenesis of MSCs after delivery of TGF-B3 and BMP2 plasmid DNA is highly dependent} on the choice of gene delivery vector

MSCs transfected using the previously described non-viral gene delivery vectors complexed to pDNA encoding for the therapeutic genes TGF- $\beta 3$ or BMP2 in combination or isolation were used to produce pellets and cultured within basal, chemically defined media conditions for 21 days. PCR analysis of gene expression at day 7 showed increased expression of the early chondrogenic differentiation marker SOX9 $[44,45]$ in the nHA and RALA pTGF- $\beta 3-p B M P 2$ co-delivery group and in the RALA-BMP2 group in comparison to the PEI treated MSCs (Fig.6.A). The MSCs transfected with RALA-pBMP2 and RALA-pTGF- $\beta 3-p B M P 2$ expressed increased levels of ACAN (a protein that forms an integral part of the extracellular matrix in cartilaginous tissue) compared to the other groups (Fig.6.B). RUNX2, a marker of endochondral ossification, was expressed at higher levels in the RALA-TGF- $\beta 3$ and nHA-TGF- $\beta 3$ groups compared to when pBMP2 and pTGF- $\beta 3$ were co-delivered using these vectors (Fig.6.C). The SOX9:RUNX2 ratio (a predictor of the osteogenic potential of MSCs where a higher value suggests a more stable chondrogenic phenotype $[44,46])$ was also higher in the nHA and RALA codelivery groups than the other groups (Fig.6.D), suggesting an increased chondrogenic potential of these vectors and pDNA combinations. 
The biochemical analysis of the pellets at 21 days of culture showed significantly higher levels of GAG (Fig.6.E) and collagen (Fig.6.F) accumulation following RALA and nHA-mediated delivery of pBMP2 and co-delivery of pTGF- $\beta 3-p B M P 2$ in comparison to PEI-mediated delivery of the same genes.

Histological examination of the pellets after 21 days of in vitro culture demonstrated higher accumulation of GAG and collagen type II deposition, as markers of chondrogenesis, in the nHApBMP2, nHA-pTGF-pBMP, RALA-pBMP2 and RALA-pTGF-pBMP groups (Fig.7.B and D). Within nHA and RALA transfected MSCs, staining for these cartilage specific markers was most intense following the co-delivery of TGF- $\beta 3$ and BMP-2. Small nodules of mineral were observed in the pellets generated using nHA transfected MSCs (Fig.7.B), except in the nHA-pTGF-pBMP2 group despite the fact that this tissue stained intensely for collagen type $X$, a marker of chondrocyte hypertrophy[47] (Fig.7.B). Staining for collagen type $X$ was also detected in the nHA-pBMP2 and RALA-pBMP2 groups (Fig.7.B and D). The PEI treated groups did not stain positively for GAG, calcium, collagen type II or collagen type $\mathrm{X}$ deposition (Fig.7.C). Collagen type I staining was also more intense in the pellets generated using nHA-BMP2 and nHA-TGF-BMP transfected MSCs (Fig.7B), but it was also present in the RALABMP2, RALA-TGF-BMP (Fig.7.D) and PEI-pBMP2 groups (Fig.7.C).

\section{DISCUSSION}

The overall aim of this study was to investigate the influence of different types of non-viral gene delivery vectors on modulating stem cell fate after the delivery of pDNA encoding for specific genes of interest. Three delivery vectors, PEI, nHA and the RALA amphipathic peptide were selected based on their chemistry and mode of action and complexed with either reporter or therapeutic genes. Systematic in vitro analysis were performed to evaluate the influence of the vectors and gene combinations on MSC fate. Even though the transfection efficiencies of these three vectors were comparable, they exerted unique effects on the metabolic activity, cellular morphology and the phenotype of MSCs. When maintained in mixed osteo-adipo media, MSCs underwent osteogenesis following transfection with $\mathrm{nHA}$ and RALA delivery vectors (complexed to reporter genes), and adipogenesis when transfected with PEI. In order to understand the influence of the delivery vector when complexed with therapeutic genes, we next evaluated the delivery of pDNA encoding for the growth factors TGF- $\beta 3$ and BMP2, in combination or in isolation, on MSC differentiation. $\mathrm{nHA}$, despite promoting significantly lower transgene expression than the other vectors, induced more robust osteogenesis in 2D and accelerated MSC hypertrophy and endochondral ossification in 3D pellet culture. On the contrary, RALA-mediated gene delivery appeared less osteogenic in both 2D and 3D culture, promoting significantly higher expression of chondrogenic markers and a more stable hyaline 
cartilage-like phenotype in pellet culture. The PEI treated MSCs failed to undergo either osteogenesis or chondrogenesis in 2D and 3D pellet culture despite high levels of therapeutic protein production.

Size, shape and surface charge have been shown to be crucial for internalization and intracellular trafficking of nanoparticle-based drug delivery systems $[48,49]$. Cationic nanoparticles of a size in the 10-200 $\mathrm{nm}$ range have been identified as the ideal to efficiently overcome physiological and cellular barriers [50,51]. But successful delivery of nucleic acids using PEI and chitosan complexes bigger than $500 \mathrm{~nm}$ and negatively charged lipoplexes and ceramic nanoparticles has also been previously reported $[26,27,52,53]$. In this study, three different vectors with different size, surface charge and chemistry were used (Fig.1). PEI and RALA were shown to have a positive $Z$ potential (Fig.1.B) due to the cationic amino groups in PEI and the guanidinium groups present in the peptide's arginine amino acids, which allow them to react with the negatively charged phosphate groups in pDNA $[30,54,55]$ (graphical abstract) to form a vector-pDNA complex with a size lower than $150 \mathrm{~nm}$ (Fig.1.A, C and E). nHA nanoparticles possessed a negative zeta potential (Fig.1.B) and a size of approximately 200-300 nm (Fig.1.A and D) after complexing with pDNA due to particle aggregation caused by the interactions between the calcium ions in the apatite and the anionic phosphate groups in the pDNA $[26,56]$ (graphical abstract). The charge and size of the nHA nanoparticles and nHA-pDNA complexes were consistent with previous reports $[26,27]$.

Even though the RALA, nHA and PEI complexes showed different chemical and physical characteristics, similar transfection efficiencies were observed after 3 days of treatment (Fig.2.A). PEI associated cytotoxicity has been previously described due to membrane and cellular organelles destabilization [57], actin cytoskeleton disruption [57-59] and an altered gene transcription $[57,60,61]$. In this study, a significant decrease in cell metabolic activity was observed in the PEI-pGFP treated group one day after transfection due to polymer-induced cytotoxicity, but this was temporary as metabolic activity recovered by day 3 (Fig.2.B), as seen in previous reports [22,35]. The hypothesized PEl-induced cytoskeleton and membrane alterations may affect the transfected MSCs, promoting a more rounded cell morphology with a less tense and organized actin cytoskeleton that is more conducive to adipogenesis [61-64]. These observations are consistent with previous reports by Godbey et al. [61] who observed that cells exposed to PEI-pDNA complexes showed a rounded phenotype $8 \mathrm{~h}$ post-transfection. On the contrary, nHA transfected cells showed a more spread morphology (Fig.2.F) with well-developed stress fibres (Fig.3.B and F). This may be due to the anionic Z potential of the nHA-pDNA complexes, which have been shown to induce actin polymerization [65] and an increased concentration of intracellular calcium which plays an important role in cell spreading and cytoskeletal events [66]. Although the cell aspect ratio and surface area of the RALA-pGFP transfected cells was significantly lower than the nHA-pGFP group at day 1 and 3 , these parameters 
were higher in comparison to the PEI-transfected cells in both time points (Fig.2.D and F). CPPs have been previously shown to induce actin remodeling and a selective activation of Rho GTPases $[67,68]$ contributing to focal adhesion and stress fiber formation $[68,69]$, which play an important role in shape-dependent control of MSC lineage commitment [64].

It is well established that morphology, cytoskeletal tension and focal adhesions have a determinant influence on stem cell differentiation towards the osteogenic, adipogenic and chondrogenic pathways $[64,70]$. While a spread phenotype is related to an increase in cytoskeletal organization, focal adhesions and osteogenesis of MSCs, a more rounded morphology can be an indication of cytoskeletal disruption and dispersed actin, which can lead to a switch towards the adipogenic pathway [62,71-73]. To investigate the role of the observed transfection-induced morphological and cytoskeletal tension changes, the treated MSCs were cultured under osteo-adipo conditions [64] and their commitment towards the osteogenic or adipogenic lineage was analysed. As might be expected for MSCs adopting a more spread morphology with a tenser cytoskeleton, RALApGFP and nHA-pGFP treated cells showed increased mineralization and mineralized nodule formation in comparison to the untransfected control group and the PEl treated group, in which calcification was suppressed (Fig.4.A, C and D). On the other hand, adipogenesis was significantly higher in the PEIpGFP transfected MSCs were the cells adopted a more rounded morphology (Fig.4.B and E). Previous studies have also shown that PEI-mediated transfection can suppress mineralization and enhance adipogeneis of stem cells [74] [75].

The ultimate goal of gene delivery in stem cell-based tissue engineering approaches is to direct stem or progenitor cells to differentiate into clinically relevant cell types. In order to achieve this objective, TGF- $\beta 3$ and BMP2 have been extensively used in gene and protein-mediated strategies for the repair of musculoskeletal tissues [76-80]. In this study the delivery of pDNAs encoding for either or both of these factors was used to assess vector-associated effects over stem cell fate. In 2D culture, in the absence of osteogenic supplements, $\mathrm{nHA}$ was the only vector capable of inducing mineralization of MSCs when pDNA encoding for either TGF- $\beta 3$ and BMP2 were delivered in isolation or combination (Fig.5.C and D). Interestingly, this occurs despite the fact that nHA-mediated transfection resulted in the lowest levels of therapeutic growth factor production (Fig.5.A and B), suggesting a synergistic effect between the osteogenic stimulus provided by $\mathrm{nHA}$ and the overexpressed proteins $[26,76]$. Of relevance to this study, Curtin et al. evaluated PEI and nHA as gene carriers for bone formation and observed that even though PEI-mediated transfection of PBMP2 and PVEGF led to higher levels of protein expression, a better healing profile was observed in vivo when nHA was used [8]. These results suggest that high levels of expression may not directly translate into an increased osteogenic effect and that the choice of delivery vector influences the bioactivity of the gene product [15]. 
Chondrogenic differentiation of transfected MSCs was also analysed. RALA-mediated delivery of $\mathrm{pBMP} 2$ and co-delivery of $\mathrm{pTGF}-\beta 3$ and $\mathrm{pBMP} 2$ resulted in the promotion of a stable hyaline cartilage-like phenotype in pellet culture, with strong staining for GAG and collagen type II deposition (Fig.7.D), and significantly higher expression of the chondrogenic markers ACAN and SOX9 (Fig.6.A and B). MSCs treated with $\mathrm{nHA}$ complexed to $\mathrm{pTGF}-\beta 3$ and $\mathrm{pBMP2}$ in isolation or combination also expressed high levels of SOX9 and ACAN (Fig.6.A and B) and stained strongly for collagen type II, but high levels of collagen type $X$ and calcium deposition suggest chondrocyte hypertrophy and progression along an endochondral pathway (Fig.7.B) [47]. This is likely due, at least in part, to the osteo-inductive nature of the nHA. The lower levels of TGF- $\beta 3$ protein production following nHAmediated gene delivery may also play a role in promoting a more endochondral phenotype, as extended growth factor presentation has been associated with a more stable cartilage phenotype [81]. In contrast to the nHA and RALA-transfected cells, the PEI-transfected MSCs promoted low levels of GAG and collagen synthesis (Fig.6.E and F) and failed to induce collagen type II deposition (Fig.7.C), despite high levels of TGF- $\beta 3$ and BMP2 expression. The observation of a more rounded phenotype of the cells treated with PEI in 2D (Fig.2.E) might suggest a propensity towards chondrogenic differentiation [82], but in this study PEI-mediated transfection failed to promote robust chondrogenesis of MSCs in pellet culture. This might be due to an altered gene transcription produced by the interaction of polycationic polymers with the host DNA upon nuclear entry $[60,61]$. The codelivery of PTGF- $\beta 3$ and PBMP2 by either RALA or nHA promoted the highest levels of chondrogenesis. Furthermore, it was observed that a suppression of calcification and a decrease in RUNX2 expression when both genes were delivered in combination in comparison to the delivery of pTGF- $\beta 3$ and pBMP2 in isolation (Fig.6.C). This is consistent with previous studies that show a synergistic effect of delivering both growth factors on chondrogenesis of MSCs [76,77].

\section{CONCLUSION}

This study demonstrates that different classes of commonly used non-viral vectors are not inert and that the chemical and physical characteristics of these nanomaterials have a strong effect on cell morphology, stress fiber formation and gene transcription in MSCs which modulates their capacity to differentiate along the osteogenic, adipogenic and chondrogenic lineages. Furthermore, the inherent effects associated with the intracellular delivery of these nanoparticle complexes was in many cases more potent than that associated with the overexpressed therapeutic genes, emphasizing the importance of understanding the cellular events upon nanoparticle entry before these approaches are used in tissue engineering and regenerative medicine strategies. The results of this study point to the need for careful and tissue-specific selection of non-viral delivery vectors to prevent undesired 
phenotypic changes and off-target effects when delivering therapeutic genes to damaged or diseased tissues.

\section{Acknowledgements}

Funding from Science Foundation Ireland through the Advanced Materials and Bioengineering Research (AMBER) center and an Investigator Programme grant (12/IA/1554), as well as through the European Research Council (StemRepair, 258463; Joint Print, 647004). Valeria Nicolosi and Christopher Hobbs would like to thank the ERC (StG 2DNanocaps) and SFI (PIYRA and AMBER) for their support and the AML for the provision of their facilities.

\section{Disclosure}

No competing financial interests exist.

\section{References}

[1] R.S. Tuan, G. Boland, R. Tuli, Adult mesenchymal stem cells and cell-based tissue engineering., Arthritis Res. Ther. 5 (2003) 32-45. doi: 10.1186/ar614.

[2] A. Uccelli, L. Moretta, V. Pistoia, Mesenchymal stem cells in health and disease, Nat. Rev. Immunol. 8 (2008) 726-736. doi:10.1038/nri2395.

[3] J.L. Santos, D. Pandita, J. Rodrigues, A.P. Pêgo, P.L. Granja, H. Tomás, Non-viral gene delivery to mesenchymal stem cells: methods, strategies and application in bone tissue engineering and regeneration., Curr. Gene Ther. 11 (2011) 46-57. doi: 10.2174/156652311794520102.

[4] M. Heyde, K.A. Partridge, R.O.C. Oreffo, S.M. Howdle, K.M. Shakesheff, M.C. Garnett, Gene therapy used for tissue engineering applications., J. Pharm. Pharmacol. 59 (2007) 329-50. doi:10.1211/jpp.59.3.0002.

[5] C. Evans, Using genes to facilitate the endogenous repair and regeneration of orthopaedic tissues., Int. Orthop. 38 (2014) 1761-9. doi:10.1007/s00264-014-2423-x.

[6] C.-Y. Lin, Y.-H. Chang, K.-C. Li, C.-H. Lu, L.-Y. Sung, C.-L. Yeh, K.-J. Lin, S.-F. Huang, T.-C. Yen, Y.-C. Hu, The use of ASCs engineered to express BMP2 or TGF- $\beta 3$ within scaffold constructs to promote calvarial bone repair., Biomaterials. 34 (2013) 9401-12. doi:10.1016/j.biomaterials.2013.08.051.

[7] J.K. Venkatesan, A. Rey-Rico, G. Schmitt, A. Wezel, H. Madry, M. Cucchiarini, rAAVmediated overexpression of TGF- $\beta$ stably restructures human osteoarthritic articular cartilage in situ., J. Transl. Med. 11 (2013) 211. doi:10.1186/1479-5876-11-211.

[8] C.M. Curtin, E.G. Tierney, K. McSorley, S.-A. Cryan, G.P. Duffy, F.J. O'Brien, Combinatorial gene therapy accelerates bone regeneration: non-viral dual delivery of VEGF and BMP2 in a collagen-nanohydroxyapatite scaffold., Adv. Healthc. Mater. 4 (2015) 223-7. doi:10.1002/adhm.201400397.

[9] S.-D. Li, L. Huang, Non-viral is superior to viral gene delivery., J. Control. Release. 123 (2007) 181-3. doi:10.1016/j.jconrel.2007.09.004. 
[10] M.A. Kay, State-of-the-art gene-based therapies: the road ahead, Nat. Rev. Genet. 12 (2011) 316-328. doi:10.1038/nrg2971.

[11] N. Bessis, F.J. GarciaCozar, M.-C. Boissier, Immune responses to gene therapy vectors: influence on vector function and effector mechanisms., Gene Ther. 11 Suppl 1 (2004) S10-7. doi:10.1038/sj.gt.3302364.

[12] E. Mastrobattista, S.A. Bravo, M. van der Aa, D.J.A. Crommelin, Nonviral gene delivery systems: From simple transfection agents to artificial viruses., Drug Discov. Today. Technol. 2 (2005) 103-9. doi:10.1016/j.ddtec.2005.04.002.

[13] H. Yin, R.L. Kanasty, A. a Eltoukhy, A.J. Vegas, J.R. Dorkin, D.G. Anderson, Non-viral vectors for gene-based therapy., Nat. Rev. Genet. 15 (2014) 541-555. doi:10.1038/nrg3763.

[14] N. Somia, I.M. Verma, Gene therapy: trials and tribulations., Nat. Rev. Genet. 1 (2000) 91-9. doi:10.1038/35038533.

[15] S. Raisin, E. Belamie, M. Morille, Non-viral gene activated matrices for mesenchymal stem cells based tissue engineering of bone and cartilage, Biomaterials. 104 (2016) 223-237. doi:10.1016/j.biomaterials.2016.07.017.

[16] C.E. Thomas, A. Ehrhardt, M. a Kay, Progress and problems with the use of viral vectors for gene therapy., Nat. Rev. Genet. 4 (2003) 346-358. doi:10.1038/nrg1066.

[17] C. Baum, O. Kustikova, U. Modlich, Z. Li, B. Fehse, Mutagenesis and oncogenesis by chromosomal insertion of gene transfer vectors., Hum. Gene Ther. 17 (2006) 253-63. doi:10.1089/hum.2006.17.253.

[18] R. Waehler, S.J. Russell, D.T. Curiel, Engineering targeted viral vectors for gene therapy., Nat. Rev. Genet. 8 (2007) 573-87. doi:10.1038/nrg2141.

[19] D. Bouard, D. Alazard-Dany, F.-L. Cosset, Viral vectors: from virology to transgene expression., Br. J. Pharmacol. 157 (2009) 153-65. doi:10.1038/bjp.2008.349.

[20] J. Bonadio, E. Smiley, P. Patil, S. Goldstein, Localized, direct plasmid gene delivery in vivo: prolonged therapy results in reproducible tissue regeneration., Nat. Med. 5 (1999) 753-9. doi:10.1038/10473.

[21] B. Ballarín-González, K.A. Howard, Polycation-based nanoparticle delivery of RNAi therapeutics: Adverse effects and solutions, Adv. Drug Deliv. Rev. 64 (2012) 1717-1729. doi:10.1016/j.addr.2012.07.004.

[22] H.Y. Yang, L.A. Vonk, R. Licht, A.M.G. Van Boxtel, J.E.J. Bekkers, A.H.M. Kragten, S. Hein, O.P. Varghese, K.A. Howard, F. Cumhur Öner, W.J.A. Dhert, L.B. Creemers, Cell type and transfection reagent-dependent effects on viability, cell content, cell cycle and inflammation of RNAi in human primary mesenchymal cells, Eur. J. Pharm. Sci. 53 (2014) 35-44. doi:10.1016/j.ejps.2013.12.006.

[23] W. Wang, W. Li, N. Ma, G. Steinhoff, Non-viral gene delivery methods., Curr. Pharm. Biotechnol. 14 (2013) 46-60. doi:10.2174/1389201011314010008.

[24] H. Lv, S. Zhang, B. Wang, S. Cui, J. Yan, Toxicity of cationic lipids and cationic polymers in gene delivery., J. Control. Release. 114 (2006) 100-9. doi:10.1016/j.jconrel.2006.04.014.

[25] A. Baker, M. Saltik, H. Lehrmann, I. Killisch, V. Mautner, G. Lamm, G. Christofori, M. Cotten, Polyethylenimine (PEI) is a simple, inexpensive and effective reagent for condensing and linking plasmid DNA to adenovirus for gene delivery., Gene Ther. 4 (1997) 773-82. doi:10.1038/sj.gt.3300471. 
[26] C.M. Curtin, G.M. Cunniffe, F.G. Lyons, K. Bessho, G.R. Dickson, G.P. Duffy, F.J. O’Brien, Innovative collagen nano-hydroxyapatite scaffolds offer a highly efficient non-viral gene delivery platform for stem cell-mediated bone formation., Adv. Mater. 24 (2012) 749-54. doi:10.1002/adma.201103828.

[27] I.M. Castaño, C.M. Curtin, G. Shaw, J. Mary Murphy, G.P. Duffy, F.J. O’Brien, A novel collagennanohydroxyapatite microRNA-activated scaffold for tissue engineering applications capable of efficient delivery of both miR-mimics and antagomiRs to human mesenchymal stem cells., J. Control. Release. 200 (2014) 42-51. doi:10.1016/j.jconrel.2014.12.034.

[28] Z.P. Xu, Q.H. Zeng, G.Q. Lu, A.B. Yu, Inorganic nanoparticles as carriers for efficient cellular delivery, Chem. Eng. Sci. 61 (2006) 1027-1040. doi:10.1016/j.ces.2005.06.019.

[29] J.S. Suh, J.Y. Lee, Y.J. Choi, H.K. You, S.-D. Hong, C.P. Chung, Y.J. Park, Intracellular delivery of cell-penetrating peptide-transcriptional factor fusion protein and its role in selective osteogenesis., Int. J. Nanomedicine. 9 (2014) 1153-66. doi:10.2147/IJN.S55433.

[30] H.O. McCarthy, J. McCaffrey, C.M. McCrudden, A. Zholobenko, A. a Ali, J.W. McBride, A.S. Massey, S. Pentlavalli, K.-H. Chen, G. Cole, S.P. Loughran, N.J. Dunne, R.F. Donnelly, V.L. Kett, T. Robson, Development and characterization of self-assembling nanoparticles using a bioinspired amphipathic peptide for gene delivery., J. Control. Release. 189C (2014) 141-149. doi:10.1016/j.jconrel.2014.06.048.

[31] T. Kaitsuka, K. Tomizawa, Cell-Penetrating Peptide as a Means of Directing the Differentiation of Induced-Pluripotent Stem Cells., Int. J. Mol. Sci. 16 (2015) 26667-76. doi:10.3390/ijms161125986.

[32] J.S. Suh, J.Y. Lee, Y.S. Choi, P.C. Chong, Y.J. Park, Peptide-mediated intracellular delivery of miRNA-29b for osteogenic stem cell differentiation, Biomaterials. 34 (2013) 4347-4359. doi:10.1016/j.biomaterials.2013.02.039.

[33] J. McCaffrey, C.M. McCrudden, A.A. Ali, A.S. Massey, J.W. McBride, M.T.C. McCrudden, E.M. Vicente-Perez, J.A. Coulter, T. Robson, R.F. Donnelly, H.O. McCarthy, Transcending epithelial and intracellular biological barriers; A prototype DNA delivery device, J. Control. Release. 226 (2016) 238-247. doi:10.1016/j.jconrel.2016.02.023.

[34] G.M. Cunniffe, F.J. O’Brien, S. Partap, T.J. Levingstone, K.T. Stanton, G.R. Dickson, The synthesis and characterization of nanophase hydroxyapatite using a novel dispersant-aided precipitation method, J. Biomed. Mater. Res. Part A. 95A (2010) 1142-1149. doi:10.1002/jbm.a.32931.

[35] E.G. Tierney, G.P. Duffy, A.J. Hibbitts, S.-A. Cryan, F.J. O'Brien, The development of non-viral gene-activated matrices for bone regeneration using polyethyleneimine (PEI) and collagenbased scaffolds., J. Control. Release. 158 (2012) 304-11. doi:10.1016/j.jconrel.2011.11.026.

[36] D.P. Lennon, A.I. Caplan, Isolation of human marrow-derived mesenchymal stem cells., Exp. Hematol. 34 (2006) 1604-5. doi:10.1016/j.exphem.2006.07.014.

[37] R. Hamid, Y. Rotshteyn, L. Rabadi, R. Parikh, P. Bullock, Comparison of alamar blue and MTT assays for high through-put screening, Toxicol. Vitr. 18 (2004) 703-710. doi:10.1016/j.tiv.2004.03.012.

[38] K.A. Kilian, B. Bugarija, B.T. Lahn, M. Mrksich, Geometric cues for directing the differentiation of mesenchymal stem cells., Proc. Natl. Acad. Sci. U. S. A. 107 (2010) 4872-7. doi:10.1073/pnas.0903269107.

[39] K.J. Livak, T.D. Schmittgen, Analysis of Relative Gene Expression Data Using Real-Time 
Quantitative PCR and the 2- $\Delta \Delta C T$ Method, Methods. 25 (2001) 402-408. doi:10.1006/meth.2001.1262.

[40] A.P. Hollander, P. V. Hatton, Biopolymer Methods in Tissue Engineering, Humana Press, New Jersey, 2003. doi:10.1385/159259428X.

[41] N.Y. Ignat'eva, N.A. Danilov, S. V. Averkiev, M. V. Obrezkova, V. V. Lunin, E.N. Sobol', Determination of hydroxyproline in tissues and the evaluation of the collagen content of the tissues, J. Anal. Chem. 62 (2007) 51-57. doi:10.1134/\$106193480701011X.

[42] G.M. Cunniffe, C.M. Curtin, E.M. Thompson, G.R. Dickson, F.J. O'Brien, Content-dependent osteogenic response of nano-hydroxyapatite; an in vitro and in vivo assessment within collagen-based scaffolds., ACS Appl. Mater. Interfaces. 8 (2016) 23477-23488. doi:10.1021/acsami.6b06596.

[43] E.J. Sheehy, T. Vinardell, C.T. Buckley, D.J. Kelly, Engineering osteochondral constructs through spatial regulation of endochondral ossification., Acta Biomater. 9 (2013) 5484-92. doi:10.1016/j.actbio.2012.11.008.

[44] C. Loebel, E.M. Czekanska, M. Bruderer, G. Salzmann, M. Alini, M.J. Stoddart, In vitro osteogenic potential of human mesenchymal stem cells is predicted by Runx2/Sox9 ratio., Tissue Eng. Part A. 21 (2015) 115-23. doi:10.1089/ten.TEA.2014.0096.

[45] H. Akiyama, Control of chondrogenesis by the transcription factor Sox9., Mod. Rheumatol. 18 (2008) 213-9. doi:10.1007/s10165-008-0048-x.

[46] R. Mhanna, A. Kashyap, G. Palazzolo, Q. Vallmajo-Martin, J. Becher, S. Möller, M. Schnabelrauch, M. Zenobi-Wong, Chondrocyte culture in three dimensional alginate sulfate hydrogels promotes proliferation while maintaining expression of chondrogenic markers., Tissue Eng. Part A. 20 (2014) 1454-64. doi:10.1089/ten.TEA.2013.0544.

[47] K. Iyama, Y. Ninomiya, B.R. Olsen, T.F. Linsenmayer, R.L. Trelstad, M. Hayashi, Spatiotemporal pattern of type $X$ collagen gene expression and collagen deposition in embryonic chick vertebrae undergoing endochondral ossification, Anat. Rec. 229 (1991) 462-472. doi:10.1002/ar.1092290405.

[48] S.E. a Gratton, P. a Ropp, P.D. Pohlhaus, J.C. Luft, V.J. Madden, M.E. Napier, J.M. DeSimone, The effect of particle design on cellular internalization pathways., Proc. Natl. Acad. Sci. U. S. A. 105 (2008) 11613-11618. doi:10.1073/pnas.0801763105.

[49] L.E. Euliss, J.A. DuPont, S. Gratton, J. DeSimone, C.N.R. Rao, G.U. Kulkarni, P.J. Thomas, P.P. Edwards, L.E. Euliss, S.G. Grancharov, S. O'Brien, T.J. Deming, G.D. Stucky, C.B. Murray, G.A. Held, G.S. Metraus, C.A. Mirkin, D.J. Milliron, S.M. Hughes, Y. Cui, L. Manna, J.B. Li, L.W. Wang, A.P. Alivisatos, T. Hyeon, L.E. Euliss, T.M. Trnka, T.J. Deming, G.D. Stucky, K. Kostarelos, A.D. Miller, F.I. Talens-Alesson, A. Salvation, M. Bryce, D. Duque, A.D. Bangham, A.D. Bangham, A.D. Bangham, X. Guo, F.C. Szoka, F.C. Szoka, D. Papahadjopoulos, E.G. Finer, A.G. Flook, H. Hauser, J. Du, Y. Tang, A.L. Lewis, S.P. Armes, A.L. Klibanov, K. Maruyama, V.P. Torchilin, L. Huang, H. Maeda, T. Sawa, T. Konno, D. Kirpotin, K.L. Hong, N. Mullah, D. Papahadjopoulos, S. Zalipsky, S. Zalipsky, M. Qazen, J.A. Walker, N. Mullah, Y.P. Quinn, S.K. Huang, Y. Lu, P.S. Low, X.Q. Pan, H.Q. Wang, R.J. Lee, K.B. Thurmond, T. Kowalewski, K.L. Wooley, K.B. Thurmond, T. Kowalewski, K.L. Wooley, R.K. O'Reilly, M.J. Joralemon, K.L. Wooley, C.J. Hawker, P. Xu, H. Tang, S. Li, J. Ren, E. Van Kirk, W.J. Murdoch, M. Radosz, Y. Shen, Y.N. Xia, G.M. Whitesides, Z. Yang, W.T.S. Huck, S.M. Clarke, A.R. Tajbakhsh, E.M. Terentjev, M.J. Vicent, R. Duncan, N. Malik, E.G. Evagorou, R. Duncan, L. Tao, G. Mantovani, F. Lecolley, D.M. Haddleton, D. Bontempo, H.D. Maynard, C.C. Lee, J.A. Mackay, J.M.J. Frechet, F.C. Szoka, D.A. Tomalia, A.M. Naylor, W.A. Goddard, J.M.J. Frechet, I. Gitsov, E.L.J. Park, N.- 
M. Hwang, M. Kang, S.C. Kim, Y. Hwang, J.-G. Park, H.-J. Noh, J.-Y. Kim, J.-H. Park, T. Hyeon, K. McAllister, P. Sazani, M. Adam, M.J. Cho, M. Rubinstein, R.J. Samulski, J.M. DeSimone, A. Horgan, B. Vincent, D. Dendukuri, K. Tsoi, T.A. Hatton, P.S. Doyle, S.Q. Xu, Z.H. Nie, M. Seo, P. Lewis, E. Kumacheva, H.A. Stone, P. Garstecki, D.B. Weibel, I. Gitlin, G.M. Whitesides, J.E. Meiring, M.J. Schmid, S.M. Grayson, B.M. Rathsack, D.M. Johnson, R. Kirby, R. Kannappan, K. Manthiram, B. Hsia, Z.L. Hogan, A.D. Ellington, M. V. Pishko, C.G. Willson, T. Bailey, B.J. Choi, M. Colburn, M. Meissl, S. Shaya, J.G. Ekerdt, S. V. Sreenivasan, C.G. Willson, S.Y. Chou, P.R. Krauss, P.J. Renstrom, M. Geissler, Y.N. Xia, Y.N. Xia, J.A. Rogers, K.E. Paul, G.M. Whitesides, S.M. Moghimi, A.C. Hunter, J.C. Murray, J.P. Rolland, E.C. Hagberg, G.M. Denison, K.R. Carter, J.M. DeSimone, J.P. Rolland, B.W. Maynor, L.E. Euliss, A.E. Exner, G.M. Denison, J.M.

DeSimone, Y.C. Dong, S.S. Feng, D. Curran, J. Grimshaw, S.D. Perera, D.J. Quick, K.S. Anseth, S. Gaidos, K.W. Powers, S.C. Brown, V.B. Krishna, S.C. Wasdo, B.M. Moudgil, S.M. Roberts, Imparting size, shape, and composition control of materials for nanomedicine, Chem. Soc. Rev. 35 (2006) 1095. doi:10.1039/b600913c.

[50] J.H. Adair, M.P. Parette, E.I. Altinoǧlu, M. Kester, Nanoparticulate alternatives for drug delivery, ACS Nano. 4 (2010) 4967-4970. doi:10.1021/nn102324e.

[51] S. Bose, S. Tarafder, Calcium phosphate ceramic systems in growth factor and drug delivery for bone tissue engineering: A review, Acta Biomater. 8 (2012) 1401-1421. doi:10.1016/j.actbio.2011.11.017.

[52] P.J. McKiernan, O. Cunningham, C.M. Greene, S.-A. Cryan, Targeting miRNA-based medicines to cystic fibrosis airway epithelial cells using nanotechnology., Int. J. Nanomedicine. 8 (2013) 3907-15. doi:10.2147/IJN.S47551.

[53] M. Kapoor, D.J. Burgess, Efficient and safe delivery of siRNA using anionic lipids: Formulation optimization studies., Int. J. Pharm. 432 (2012) 80-90. doi:10.1016/j.ijpharm.2012.04.058.

[54] O. Boussif, F. Lezoualc'h, M.A. Zanta, M.D. Mergny, D. Scherman, B. Demeneix, J.P. Behr, A versatile vector for gene and oligonucleotide transfer into cells in culture and in vivo: polyethylenimine., Proc. Natl. Acad. Sci. U. S. A. 92 (1995) 7297-301. doi:10.1073/pnas.92.16.7297.

[55] M. Oba, Y. Demizu, H. Yamashita, M. Kurihara, M. Tanaka, Plasmid DNA delivery using fluorescein-labeled arginine-rich peptides, Bioorg. Med. Chem. 23 (2015) 4911-4918. doi:10.1016/j.bmc.2015.05.025.

[56] M. Okazaki, Y. Yoshida, S. Yamaguchi, M. Kaneno, J.C. Elliott, Affinity binding phenomena of DNA onto apatite crystals., Biomaterials. 22 (2001) 2459-64. doi: 10.1016/S01429612(00)00433-6.

[57] A.K. Larsen, A.C. Hunter, L. Parhamifar, S.M. Moghimi, T.L. Andresen, Polycation cytotoxicity: a delicate matter for nucleic acid therapy-focus on polyethylenimine, Soft Matter. 6 (2010) 4001. doi:10.1039/c000190b.

[58] S. Grosse, Y. Aron, G. Thévenot, M. Monsigny, I. Fajac, Cytoskeletal involvement in the cellular trafficking of plasmid/PEI derivative complexes., J. Control. Release. 122 (2007) 1117. doi:10.1016/j.jconrel.2007.06.015.

[59] G.C. Wong, J.X. Tang, A. Lin, Y. Li, P.A. Janmey, C.R. Safinya, Hierarchical self-assembly of Factin and cationic lipid complexes: stacked three-layer tubule networks., Science. 288 (2000). doi: 10.1126/science.288.5473.2035.

[60] S. Akhtar, Non-viral cancer gene therapy: Beyond delivery, Gene Ther. 13 (2005) 739-740. doi:10.1038/sj.gt.3302692. 
[61] W.T. Godbey, K.K. Wu, A.G. Mikos, Poly(ethylenimine)-mediated gene delivery affects endothelial cell function and viability, Biomaterials. 22 (2001) 471-480. doi:10.1016/S01429612(00)00203-9.

[62] T. Feng, E. Szabo, E. Dziak, M. Opas, Cytoskeletal disassembly and cell rounding promotes adipogenesis from ES cells, Stem Cell Rev. Reports. 6 (2010) 74-85. doi:10.1007/s12015-0109115-8.

[63] C. Margadant, L. Cremers, A. Sonnenberg, J. Boonstra, MAPK uncouples cell cycle progression from cell spreading and cytoskeletal organization in cycling cells., Cell. Mol. Life Sci. 70 (2013) 293-307. doi:10.1007/s00018-012-1130-2.

[64] R. McBeath, D.M. Pirone, C.M. Nelson, K. Bhadriraju, C.S. Chen, Cell shape, cytoskeletal tension, and RhoA regulate stem cell lineage commitment, Dev. Cell. 6 (2004) 483-495. doi:10.1016/S1534-5807(04)00075-9.

[65] C.P. Ng, T.T. Goodman, I.-K. Park, S.H. Pun, Bio-mimetic surface engineering of plasmidloaded nanoparticles for active intracellular trafficking by actin comet-tail motility., Biomaterials. 30 (2009) 951-8. doi:10.1016/j.biomaterials.2008.10.059.

[66] B.A. Kruskal, S. Shak, F.R. Maxfield, Spreading of human neutrophils is immediately preceded by a large increase in cytoplasmic free calcium., Proc. Natl. Acad. Sci. U. S. A. 83 (1986) 291923. http://www.ncbi.nlm.nih.gov/pubmed/3458251 (accessed June 16, 2016).

[67] F. Heitz, M.C. Morris, G. Divita, Twenty years of cell-penetrating peptides: from molecular mechanisms to therapeutics., Br. J. Pharmacol. 157 (2009) 195-206. doi:10.1111/j.14765381.2009.00057.x.

[68] C. Foerg, U. Ziegler, J. Fernandez-Carneado, E. Giralt, H.P. Merkle, Differentiation restricted endocytosis of cell penetrating peptides in MDCK cells corresponds with activities of RhoGTPases, Pharm. Res. 24 (2007) 628-642. doi:10.1007/s11095-006-9212-1.

[69] K. Burridge, K. Wennerberg, Rho and Rac Take Center Stage, Cell. 116 (2004) 167-179. doi:10.1016/S0092-8674(04)00003-0.

[70] P.S. Mathieu, E.G. Loboa, Cytoskeletal and focal adhesion influences on mesenchymal stem cell shape, mechanical properties, and differentiation down osteogenic, adipogenic, and chondrogenic pathways., Tissue Eng. Part B. Rev. 18 (2012) 436-44. doi:10.1089/ten.TEB.2012.0014.

[71] K.A. Kilian, B. Bugarija, B.T. Lahn, M. Mrksich, Geometric cues for directing the differentiation of mesenchymal stem cells., Proc. Natl. Acad. Sci. U. S. A. 107 (2010) 4872-7. doi:10.1073/pnas.0903269107.

[72] J.P. Rodríguez, M. González, S. Ríos, V. Cambiazo, Cytoskeletal organization of human mesenchymal stem cells (MSC) changes during their osteogenic differentiation, J. Cell. Biochem. 93 (2004) 721-731. doi:10.1002/jcb.20234.

[73] H. Sonowal, A. Kumar, J. Bhattacharyya, P.K. Gogoi, B.G. Jaganathan, Inhibition of actin polymerization decreases osteogeneic differentiation of mesenchymal stem cells through p38 MAPK pathway., J. Biomed. Sci. 20 (2013) 71. doi:10.1186/1423-0127-20-71.

[74] W.J. King, N.A. Kouris, S. Choi, B.M. Ogle, W.L. Murphy, Environmental parameters influence non-viral transfection of human mesenchymal stem cells for tissue engineering applications, Cell Tissue Res. 347 (2012) 689-699. doi:10.1007/s00441-011-1297-0.

[75] L. Zhao, A. Kutikov, J. Shen, C. Duan, J. Song, G. Han, Stem cell labeling using polyethylenimine 
conjugated ( $\alpha$-NaYbF4:Tm3+)/CaF2 upconversion nanoparticles., Theranostics. 3 (2013) 249257. doi:10.7150/thno.5432.

[76] T. Gonzalez-Fernandez, E.G. Tierney, G.M. Cunniffe, F.J. O'Brien, D.J. Kelly, Gene Delivery of TGF- $\beta 3$ and BMP2 in an MSC-Laden Alginate Hydrogel for Articular Cartilage and Endochondral Bone Tissue Engineering., Tissue Eng. Part A. 22 (2016) 776-87. doi:10.1089/ten.TEA.2015.0576.

[77] B. Shen, A. Wei, H. Tao, A.D. Diwan, D.D.F. Ma, BMP-2 enhances TGF-beta3-mediated chondrogenic differentiation of human bone marrow multipotent mesenchymal stromal cells in alginate bead culture., Tissue Eng. Part A. 15 (2009) 1311-1320. doi:10.1089/ten.tea.2008.0132.

[78] L.D. Loozen, F. Wegman, F.C. Öner, W.J. a. Dhert, J. Alblas, Porous bioprinted constructs in BMP-2 non-viral gene therapy for bone tissue engineering, J. Mater. Chem. B. 1 (2013) 6619. doi:10.1039/c3tb21093f.

[79] J. Hao, Y. Yao, R.R. Varshney, L. Wang, C. Prakash, H. Li, D.-A. Wang, Gene transfer and living release of transforming growth factor-beta3 for cartilage tissue engineering applications., Tissue Eng. Part C. Methods. 14 (2008) 273-80. doi:10.1089/ten.tec.2008.0163.

[80] J.M. Brunger, N.P.T. Huynh, C.M. Guenther, P. Perez-Pinera, F.T. Moutos, J. Sanchez-Adams, C. a Gersbach, F. Guilak, Scaffold-mediated lentiviral transduction for functional tissue engineering of cartilage., Proc. Natl. Acad. Sci. U. S. A. 111 (2014) E798-806. doi:10.1073/pnas.1321744111.

[81] K. Liu, G.D. Zhou, W. Liu, W.J. Zhang, L. Cui, X. Liu, T.Y. Liu, Y. Cao, The dependence of in vivo stable ectopic chondrogenesis by human mesenchymal stem cells on chondrogenic differentiation in vitro, Biomaterials. 29 (2008) 2183-2192. doi:10.1016/j.biomaterials.2008.01.021.

[82] L. Gao, R. McBeath, C.S. Chen, Stem cell shape regulates a chondrogenic versus myogenic fate through rac1 and N-cadherin, Stem Cells. 28 (2010) 564-572. doi:10.1002/stem.308.

Graphical abstract (experimental design): MSCs were transfected using either ceramic ( $\mathrm{nHA}$ ), cationic polymer (PEI) or amphipathic peptide (RALA) non-viral gene delivery vectors, complexed to plasmid DNA ( $p D N A$ ) encoding for either reporter or therapeutic genes. After transfection, the adipogenic, osteogenic and chondrogenic potential of the treated MSCs were assessed in either 2D (monolayer culture in bi-potent media) and 3D (pellet culture) in order to elucidate the effects of the gene transfer nanomaterial on MSC fate.

Fig.1. Size (A) and charge (B) of the nHA-pGFP, PEI-pGFP and RALA-pGFP complexes. $\left({ }^{*}\right)$ denotes significance $(n=3, p<0.05)$ in comparison to the rest of the groups. TEM images of the nHA-pGFP $(C)$, PEI-pGFP (D) and RALA-pDNA (E) complexes. Scale bar, $200 \mathrm{~nm}$. 
Fig.2. (A) Percentage of GFP positive cells at days 3 and 7 post transfection with nHA-pGFP, PEI-pGFP and RALA-pGFP complexes. (B) Cell metabolic activity (\% of untransfected control) at days 1 and 3 post transfection. (C) Fluorescent inverted microscopy images of the transfected MSCs and day 1 and 3 after transfection. Scale bar, $200 \mu \mathrm{m}$. (D) Cell surface area, (E) circularity and (F) cell aspect ratio of the transfected cells at days 1 and 3 post transfection. $\left({ }^{*}\right)$ denotes significance $(n=4$ for $A$ and $B, n=6$ for $D$, $E$ and $F, p<0.05)$ in comparison to all groups in the same time point; $\left({ }^{* *}\right)$ denotes significance $(n=4$ for $A$ and $B, n=6$ for $D, E$ and $F, p<0.01)$ in comparison to all groups in the same time point; $\left({ }^{* * *}\right)$ denotes significance $(n=4$ for $A$ and $B, n=6$ for $D, E$ and $F, p<0.001$ ) in comparison to all groups in the same time point.

Fig.3. Immunofluorescent images of cells stained for vinculin (green), F-actin (red) and nuclei (blue) at day $1(A-D)$ and $3(E-H)$ after transfection with nHA-pLUC (B,F), PEI-pLUC (C,G) and RALA-pLUC (D,H) complexes and the untreated control $(A, E)$. Scale bar, $50 \mu \mathrm{m}$.

Fig.4. Assessment of the osteogenic and adipogenic potential of MSCs transfected with pGFP complexed to either $\mathrm{nHA}, \mathrm{PEI}$ and RALA after 14 days of in vitro 2D culture in basal and osteo-adipo

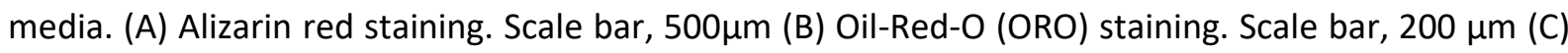
Fluorescent microscope images of the GFP expressing MSCs after 14 days of in vitro 2D culture. Scale bar, $100 \mu \mathrm{m}$. (D) Quantification of alizarin red (AR) staining of the transfected monolayers. (E) Quantification of oil-red-o (ORO) staining of the transfected monolayers. $(*)$ denotes significance $(n=3$, $p<0.05)$ in comparison to all groups in the same culture condition; (a) denotes significance $(n=3$, $p<0.05)$ in comparison to PEI-pGFP in the same culture condition; (b) denotes significance $(n=3, p<0.05)$ in comparison to the control group in the same culture condition.

Fig.5. (A) TGF- $\beta 3$ and (B) BMP2 protein expression after 3 and 7 days of MSC in vitro 2D transfection using $\mathrm{nHA}, \mathrm{PEI}$ and RALA as gene delivery vectors. (C) Alizarin red staining. Scale bar, $500 \mu \mathrm{m}$. (D) Total calcium content of the transfected monolayers after 14 days of in vitro culture. $\left({ }^{*}\right)$ denotes significance $(n=3, p<0.01)$ in comparison to all the groups in the same time point. $\left(^{* *}\right)$ denotes significance $(n=3$, $p<0.01)$ in comparison to all the groups in the same time point. $(* * *)$ denotes significance $(n=3$, $p<0.001$ ) in comparison to all the groups in the same time point.

Fig.6. Relative expression levels of SOX9 (A), ACAN (B) and RUNX2 (C) in the nHA, PEI and RALA transfected pellets with either pGFP, pTGF- $\beta 3$ (pTGF), pBMP2 (pBMP) or a combination of both (pTGFpBMP) after 7 days of in vitro culture. (D) SOX9:RUNX2 relative expression levels ratio. Total GAG (E) and collagen (F) content in the $\mathrm{nHA}, \mathrm{PEI}$ and RALA transfected pellets after 21 days of in vitro culture. (c) denotes significance $(n=4, p<0.05)$ in comparison to the PEI-pTGF and PEI-pTGF-pBMP groups. (d) denotes significance $(n=4, p<0.05)$ in comparison to all PEI transfected groups. (e) denotes significance 
$(n=4, p<0.05)$ in comparison to all the rest RALA-transfected groups. $\left({ }^{* * *}\right)$ denotes significance $(n=4$, $p<0.001$ ) in comparison to all the groups. The dotted line indicates the untransfected control (fold change $=1$ ).

Fig.7. Histological examination of the untransfected MSC pellets $(A)$ and transfected MSC pellets with either (B) nHA, (C) PEI or (D) RALA, complexed to pDNA encoding for either GFP, TGF- $\beta 3$, BMP2 or a combination of both, after 21 days of in vitro culture. sGAG histological examination through Alcian blue staining; calcium deposition histological examination through alizarin red; collagen type II, collagen type I and collagen type X immunostaining. Scale bar, $200 \mu \mathrm{m}$. Black arrows indicate details of localised specific matrix deposition. 


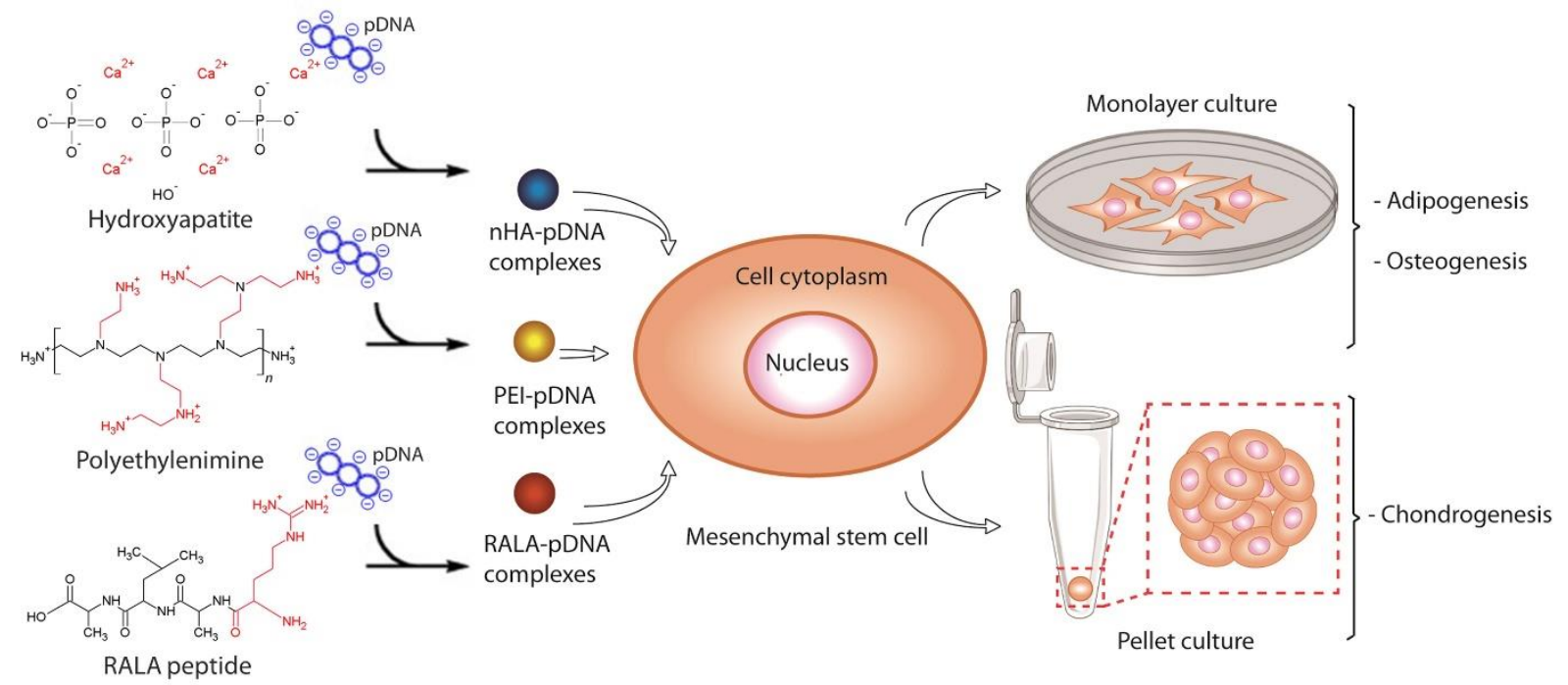

Graphical abstract

A

B
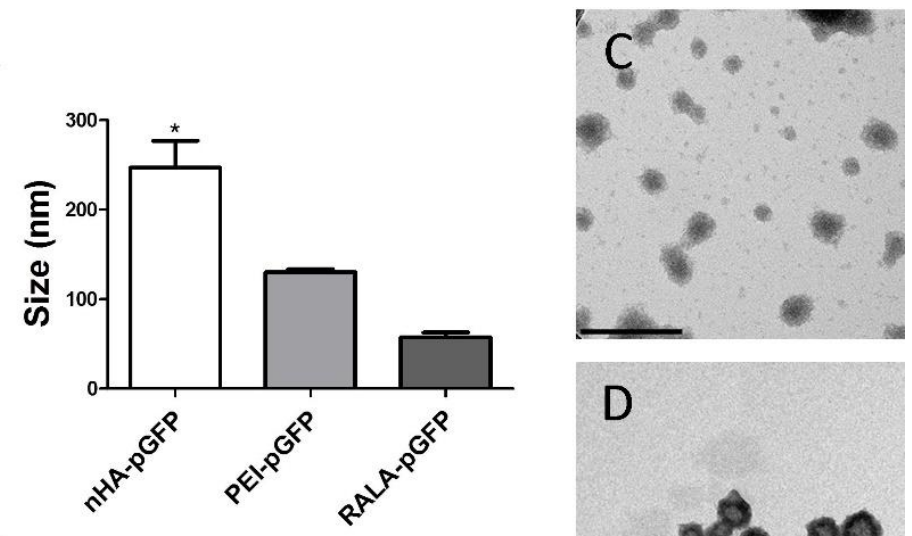

D
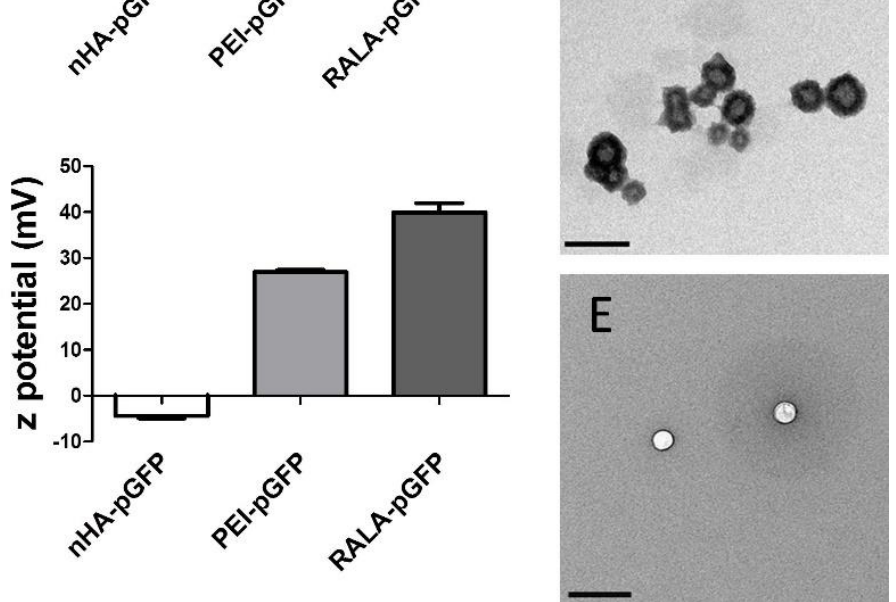

Fig.1. 


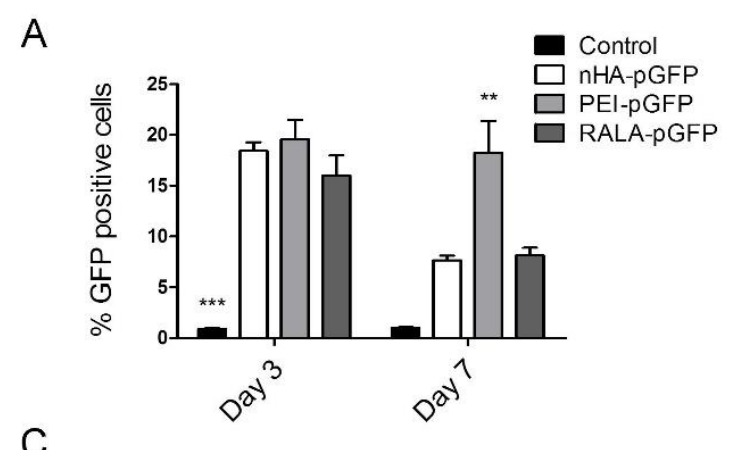

C

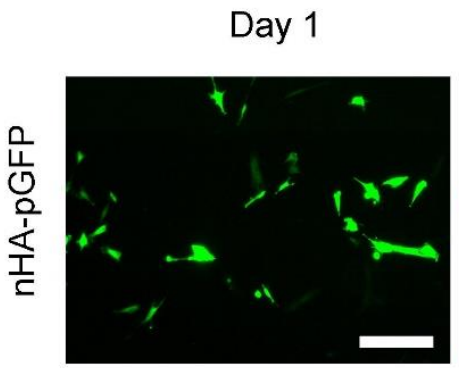

Day 3
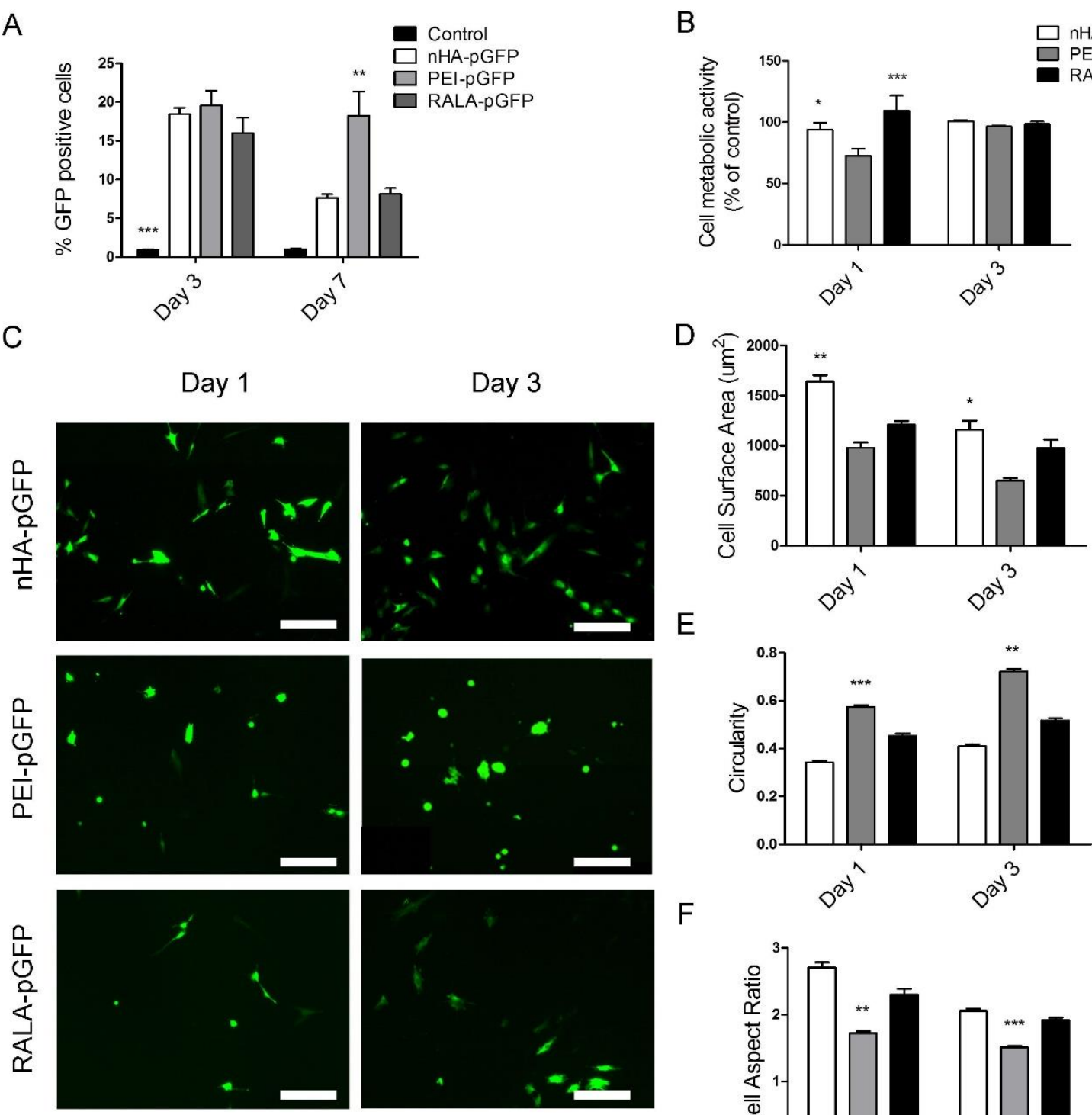

E
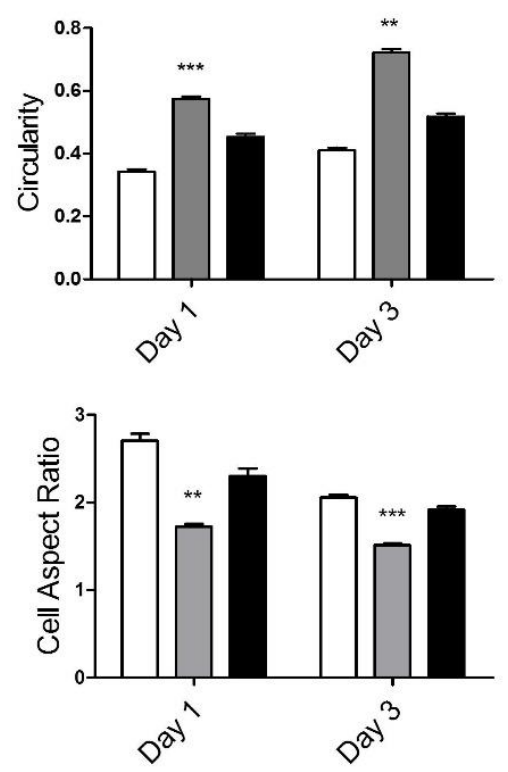

Fig.2. 

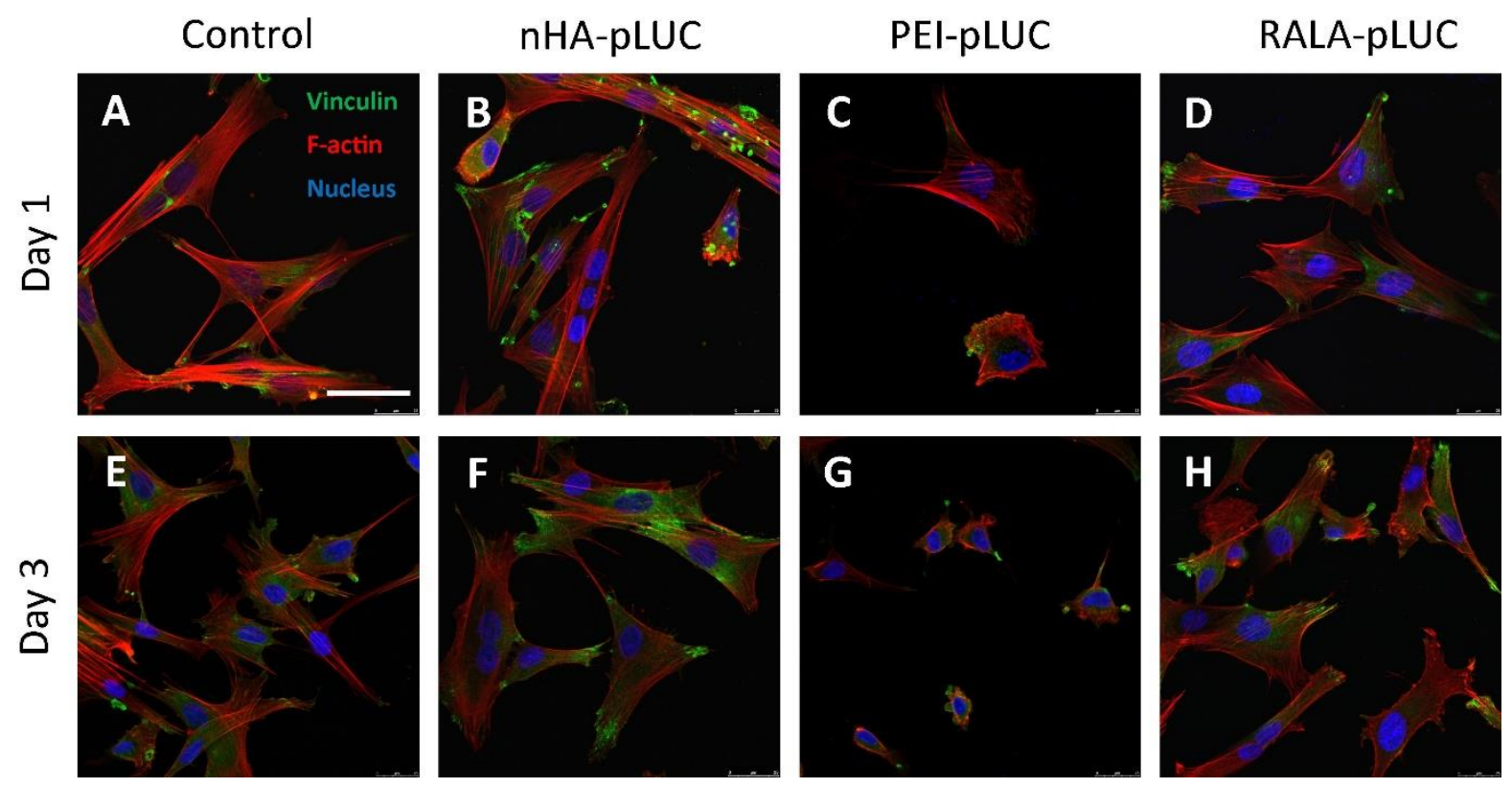

Fig.3.

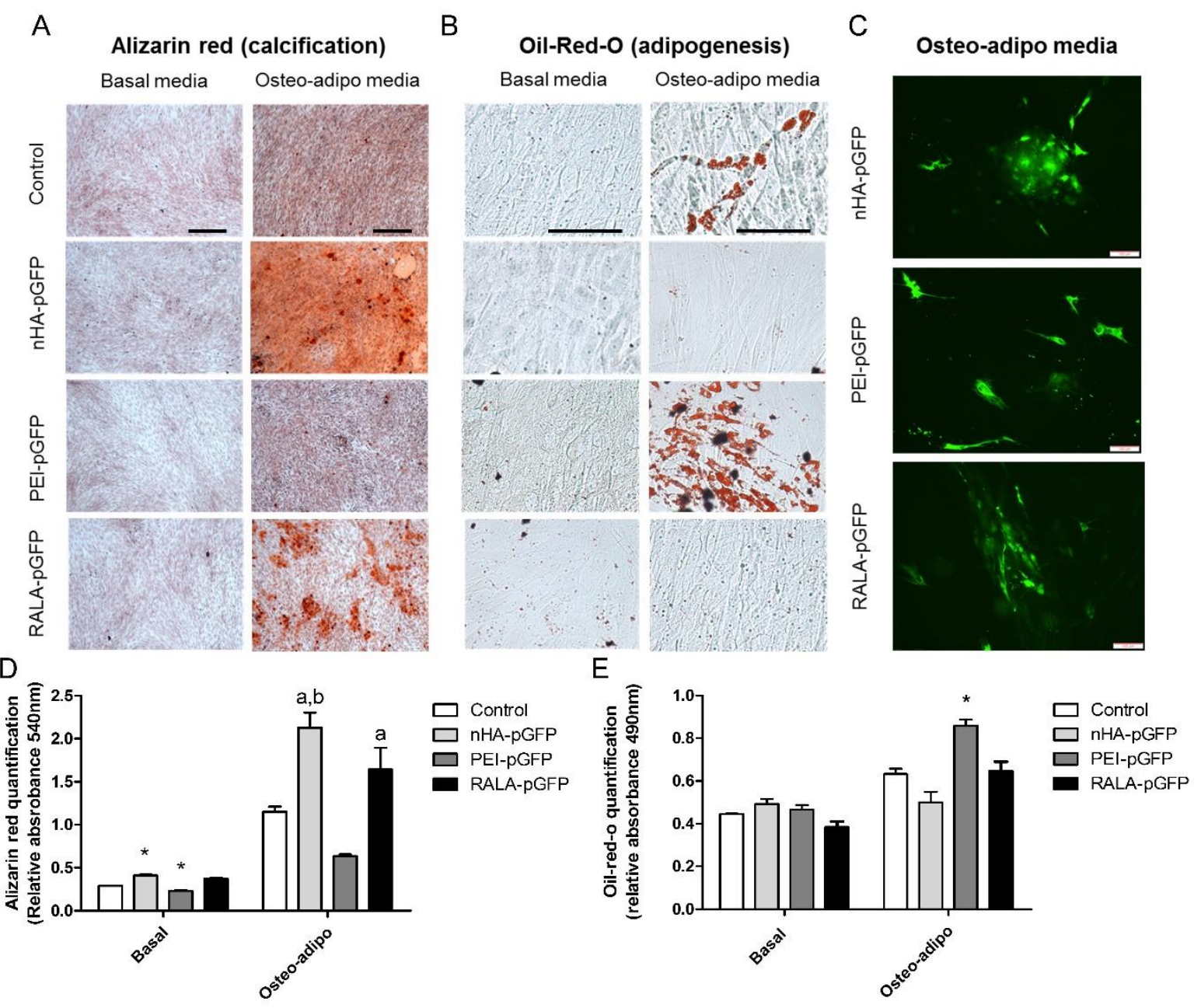

Fig.4. 
A

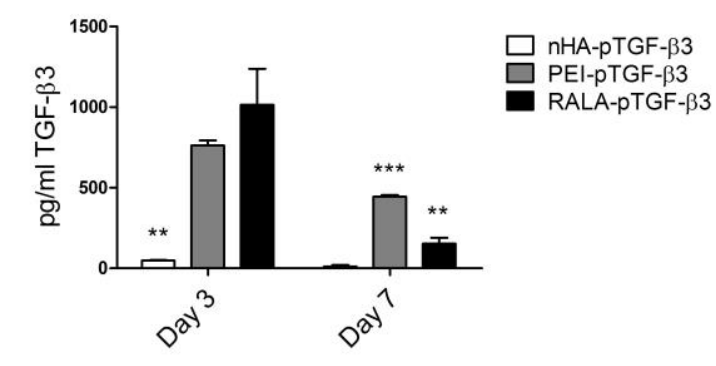

C $\quad$ PGFP $\quad$ PTGF- $\beta 3$
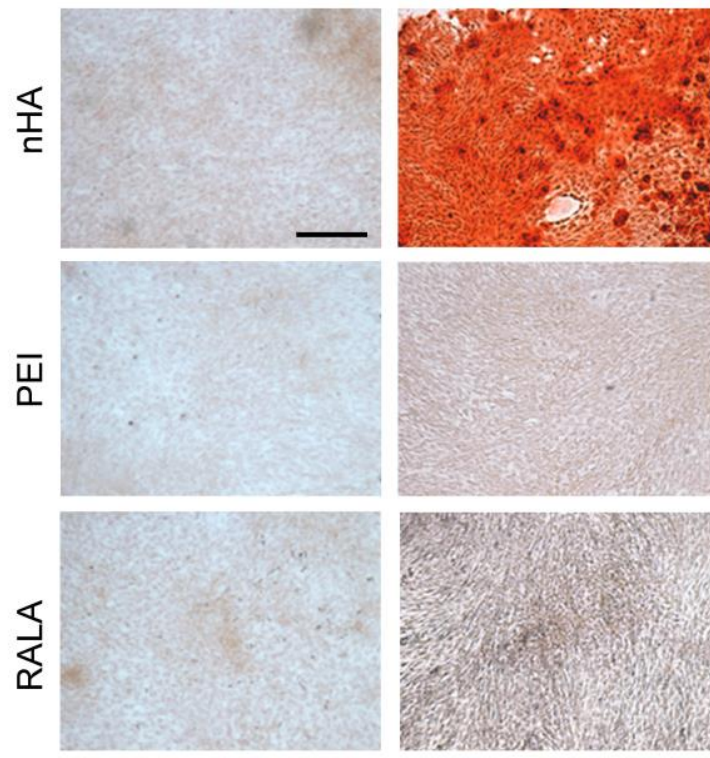

B

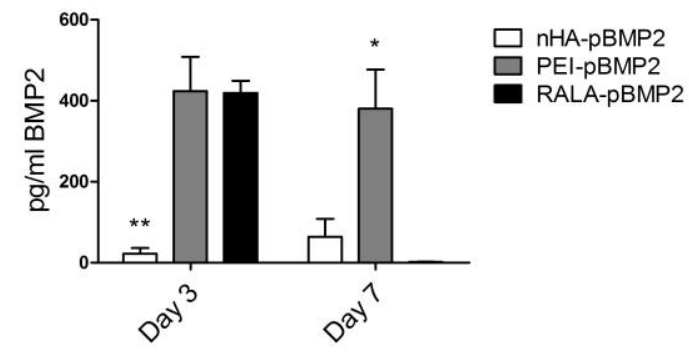

pBMP2

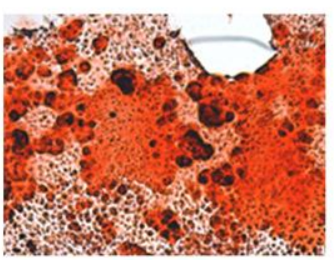

pTGF-pBMP2
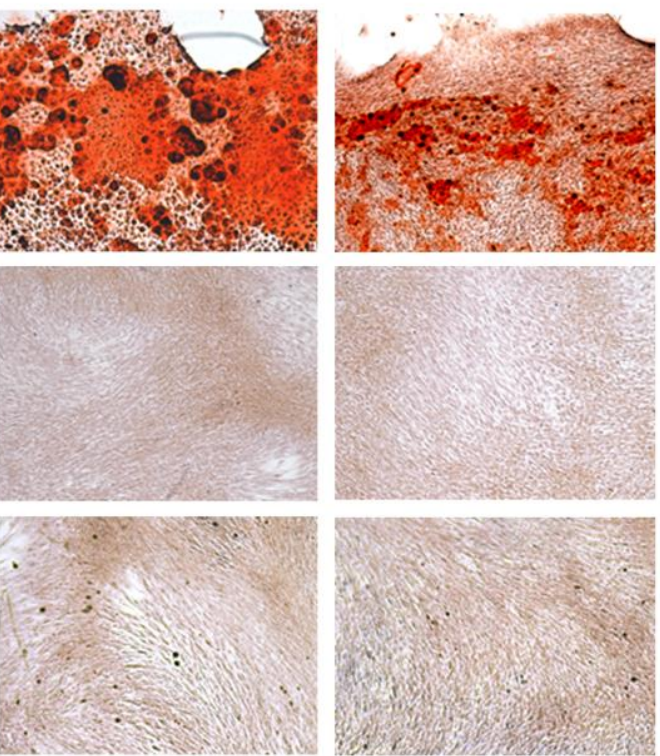

D

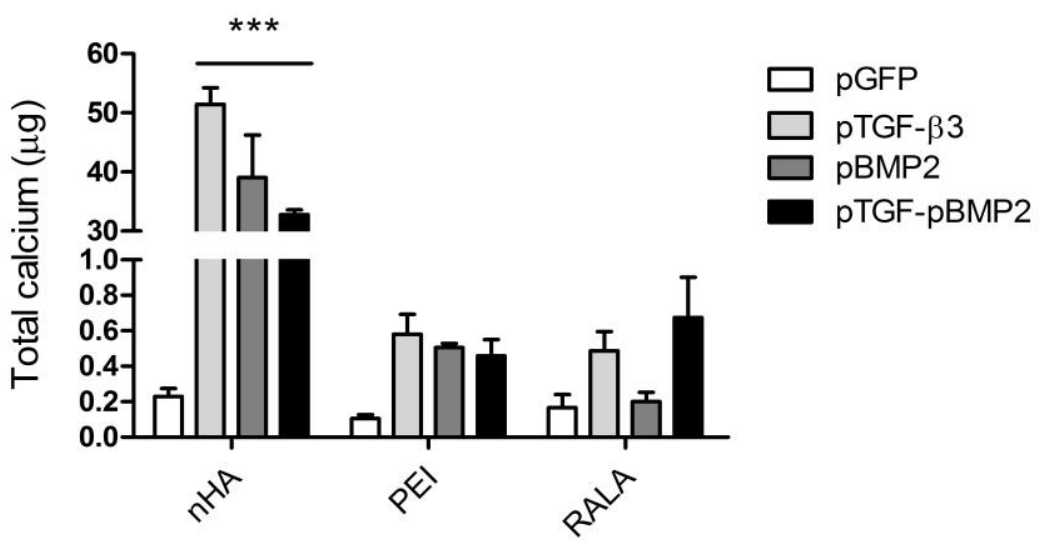

Fig.5. 

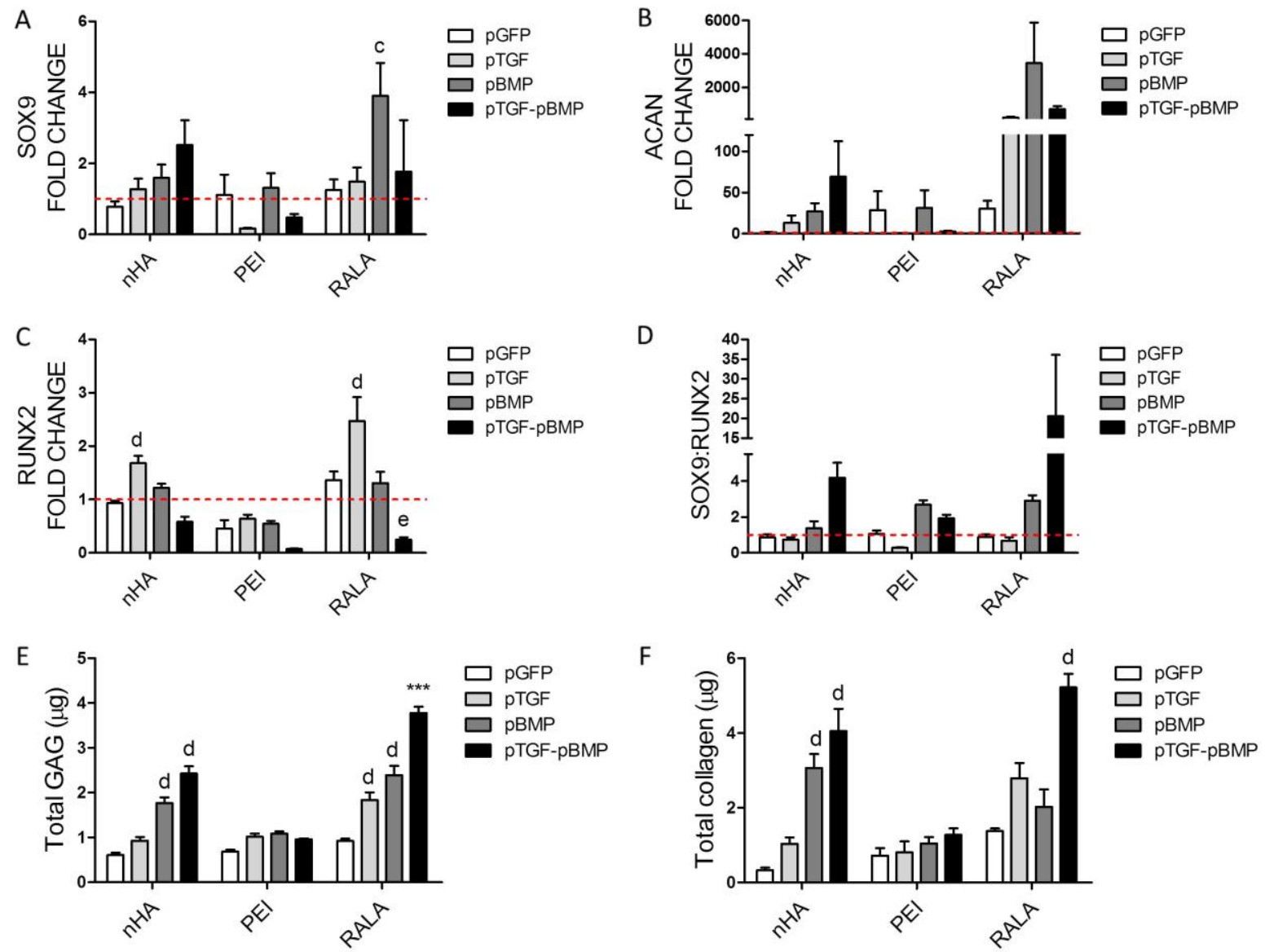

Fig.6. 


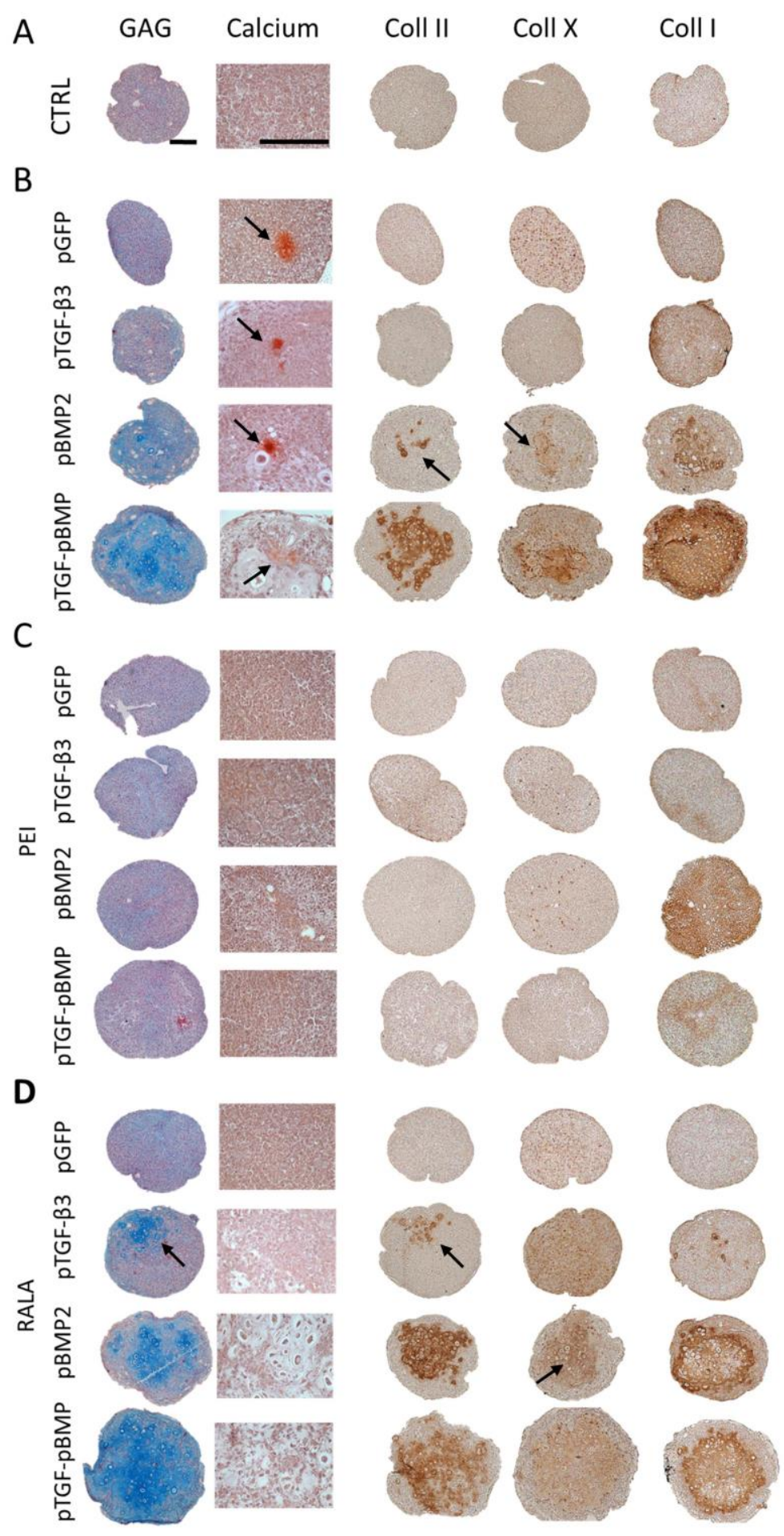

Fig.7. 